\title{
LEARNING IN PRACTICE: \\ WHAT ORGANIZATIONAL AND MANAGEMENT LITERATURE CAN CONTRIBUTE TO PROFESSIONAL AND OCCUPATIONAL DEVELOPMENT
}

Remei Agulles

Ma Julia Prats 


\title{
LEARNING IN PRACTICE: \\ WHAT ORGANIZATIONAL AND MANAGEMENT LITERATURE CAN CONTRIBUTE TO PROFESSIONAL AND OCCUPATIONAL DEVELOPMENT*
}

\author{
Remei Agulles ${ }^{1}$ \\ $M^{a}$ Julia Prats ${ }^{2}$
}

\begin{abstract}
Organizations, occupations and professions usually devote considerable effort to training and other forms of purposive hands-on processes, so that their members learn the practices that belong to their job. However, this investment does not always pay off, or, at least, in a way proportional to the effort. It is also true that not all learning occurs through these mechanisms: members of a firm or an occupation continue to learn - or may forget what they learned during their practice. For these reasons, it seems natural that both practitioners and scholars of different fields should have devoted and should continue to devote so much attention to learning processes, especially those that occur in work practice. The present paper intends to provide an overview of the contributions that management and organizational literature has made to the field of professional and occupational development by focusing on how this literature understands learning in practice.
\end{abstract}

Keywords: practical learning, organizational learning, knowledge management, professional expertise, personal development, obstacles to learning, information technologies

\footnotetext{
* This paper has been written with the support of the IESE Business School Research Department and the Home Renaissance Foundation, whose main purpose is "to bring about change in our understanding of the professional dimension of the work of the home for a well-balanced society" (www.homerenaissancefoundation.org, accessed 12 July 2011). Hence, this work also aims to contribute to this goal by providing another point of view regarding professional and occupational practice of the work of the home.

${ }^{1}$ Research Assistant, IESE

${ }^{2}$ Associate Professor, Entrepreneurship, IESE
} 


\section{LEARNING IN PRACTICE: WHAT ORGANIZATIONAL AND MANAGEMENT LITERATURE CAN CONTRIBUTE TO PROFESSIONAL AND OCCUPATIONAL DEVELOPMENT}

Organizations, occupations and professions usually devote considerable effort to training and other forms of purposive hands-on processes, so that their members learn the practices that belong to their job. However, this investment does not always pay off, or, at least, in a way proportional to the effort. It is also true that not all learning occurs through these mechanisms: members of a firm or an occupation continue to learn - or may forget what they learned during their practice.

For these reasons, it seems natural that both practitioners and scholars of different fields should have devoted and should continue to devote so much attention to learning processes, especially those that occur in work practice.

The notion of learning in this paper will be that of acquisition of new knowledge. We will here include all processes of knowledge creation, acquisition and re-combination. By practical knowledge we will understand the knowledge which is intrinsic to action.

\section{Introduction}

\section{Practical Learning, Professions and Occupations, and Business}

The present essay seeks to provide an overview of the contributions that management literature has made to the field of professional and occupational development. The focus of the paper is eminently practical - i.e., it explores an area that has been designed with names such as learning in practice, practical learning, on-the-job learning, work-based learning and the like - but, at the same time, we distance ourselves to a certain extent from the specific methods and mechanisms applied by firms or described in the HR literature. ${ }^{1}$ We will focus instead on the basic assumptions and concepts that may be discovered in the literature covering this wide area.

We argue that this view is particularly apt in the business world. On one hand, business management is, above all, a practice, and literature concerning the business world has historically followed a clearly practical - or even pragmatic - approach. On the other hand,

\footnotetext{
${ }^{1}$ A good summary of practical techniques and methods can be found in Cheetham and Chivers' (2001) review.
} 
businesses - whether manufacturing companies, management companies or service firms encompass a wide range of professions and occupations whose practice is performed within the organization and aligned with its ends. It is in the performance of this practice that managers, professionals and other employees develop over time, and this is what is meant by practical learning, as opposed to theoretical learning, which usually takes place in academic settings and is conveyed by lectures, publications and similar means.

The notion of practical learning leads to that of practical knowledge - i.e., the knowledge referring to practice and that is only acquired in practice. This is not without risk. Alvesson (1993) warns that, in the same way that understanding 'knowledge' only in its formal, sciencebased, theoretical acceptance is too reductive, using instead a broader notion of knowledge such as encompassing diverse skills in addition to systematic knowledge - runs the risk of meaning nothing and everything. We argue that while theoretical and practical knowledge is interrelated, a distinction could be made between them, and, therefore, the 'knowledge' component of skills and habits should be studied separately. This means that there is a way to learn the first type of knowledge - theoretical learning - and a way to learn the second practical learning. We will focus on the latter.

Firms are settings in which professional expertise is developed through the practice, and this development is what we understand by practical learning.

Our focus is on how this learning occurs; we will not distinguish here between 'manual' and 'intellectual' professions and occupations. In our opinion, what the concept of manual adds to a practice is the need to develop and put into action a series of bodily skills required by the actual practice, which are not demanded by intellectual jobs. In fact, many examples provided by leading theorists regarding the practice of professions and occupations within organizations and businesses refer to jobs with a manual aspect, such as midwives or tailors (Lave and Wenger, 1991), flute makers (Cook and Brown, 1999; Cook and Yanow, 1993), surgical teams and nurses (Edmondson, 1999; Pisano et al., 2001; Tucker et al., 2007). Therefore, here we will speak about practical knowledge without distinguishing between intellectual and manual practices.

Focusing on individual practical learning does not mean ignoring the context of this learning, which is the organization, the company. In particular, literature on organizational learning (OL) - i.e., how organizations as entities learn - may provide interesting insights to our subject. Applying concepts from OL theory to individual learning may seem problematic, and certainly must not be done uncritically. However, there are reasons that support this decision.

In their classification of theories on OL, Cook and Yanow (1993) have noted that many developments under the denomination of OL have actually focused on how an individual learns in an organization. A second group of scholars has focused on the organization, applying findings or theories coming from research on individual learning to the organization. Cook and Yanow (1993) explain the conceptual and methodological problems posed by these two approaches from the point of view of OL theory, all of them stemming from the application of the label organizational to something that is actually individual. We avoid these problems by adopting an individual point of view, but always taking into account his or her context. We consider that this approach allows us to benefit from the contributions of both groups and also to use concepts and ideas generated by a third group of authors described by Cook and Yanow: that which can be considered truly organizational. Thus, social processes, communities of practice, organizational routines, organizational culture and other similar concepts will help us understand the influence that the environment has on the learning individual. 


\section{Practical Learning and Tacit Knowledge}

We have already talked about the distinction between practical learning and theoretical learning, and about the difference between organizational learning vs. individual learning. The notion of tacit knowledge remains to be approached, because it is closely related to practical learning.

The concept of tacit knowledge appears in Polanyi's (1966) work, introduced by his famous statement that "we know more than we can tell" (p. 4), and it is understood as the unidentifiable or inexpressible dimension that underlies all human knowing (see also Spender, 1996). Polanyi characterizes this dimension as the one that enables the integration of different components of experience. Thus, he expressly links tacit knowledge both to creativity and expert practice: in its highest manifestation, to scientists and artistic geniuses; in a lower form, to "the expert diagnostician", and, he adds, "we may put in the same class the performance of skills, whether artistic, athletic, or technical” (Polanyi, 1966, p. 6).

This concept has been opposed to explicit knowledge, understood as that which may be easily codified and transferred, and often also associated to abstract, objectified knowledge (Nonaka, 1994; Nonaka et al., 2006). Formal instruction is one of the means through which explicit knowledge can be acquired.

After Polanyi, the notion of tacit knowledge has been taken up in both the OL and the knowledge management (KM) literature, and this is the reason why it has been described in many different ways: as a social preconscious collective knowledge based on all knowledge (Spender, 1996); as the facet of knowledge that is unspeakable (Cook and Brown, 1999); as that which must be taught indirectly (Baumard, 2002); as a characteristic of higher levels of knowledge (Akbar, 2003); as rooted in action (Alavi and Leidner, 2001; Raelin, 1997).

Spender (1996, p. 54) noted that some have interpreted Polanyi as identifying tacit with action, "while seeming to leave explicit knowledge in the positively defined domain of abstraction from action." This is not our intention: there is practical knowledge that can be explained (for example, the instructions for a device, a cooking recipe, a process diagram, or a firm's code of conduct), and also theoretical or abstract knowledge which is tacit (such as, for example, that held by a mathematics genius). Polanyi himself sees a tacit dimension in both theoretical and practical knowledge. Similarly, Nonaka (1994, p. 16) states that the concept of tacit knowledge relates both to cognitive and technical elements, the former being mental models (i.e., paradigms or beliefs), and the latter being "know-how, crafts, and skills that apply to specific contexts".

While we do not deem all tacit knowledge to be practical, looking at it from the other direction, we could say that what is learned in practice is mostly tacit, which means that it is acquired within the individual's action and his or her interaction with other individuals and certain objects, and not easily by verbal communication (Baumard, 2002; Cook and Brown, 1999; Cook and Yanow, 1993).

All of this has interesting implications for learners of a practice. Those implications will be addressed in the course of this paper, but we will give a few examples here. First of all, the high level of tacitness in practical knowledge makes it especially difficult to manage using IT systems, which always require some kind of codification (Alavi and Leidner, 2001; Hansen et al., 1999; Stein and Zwass, 1995). Related to this, learning in practice requires face-to-face or, rather, side-by-side - interaction (Brown and Duguid, 1998; Coff et al., 2006; Davenport et al., 1998). Furthermore, it is difficult to replicate and spread tacit knowledge without making it imitable - and, hence, without losing competitive advantage (Coff et al., 2006) -, and this has 
significant consequences for, say, the replication and diffusion of best practices across the organization. Finally, it has been said that formal instruction is an example of transmission of explicit knowledge; therefore, it will be interesting to address the role of formal instruction - if any - in practical learning.

We will devote the last subsection of this introduction to briefly commenting on the different positions that lie at the root of the great diversity of approaches to learning in the business and organizational literature.

\section{Different Theoretical Bases for Learning}

Before describing the different contributions to this paper's main theme, it may be interesting to highlight that the lack of agreement in both the fields of OL and KM about what learning is or how it occurs (Argote, 2005; Easterby-Smith and Lyles, 2003; Hazlett et al., 2005; Spender, 2008) is due to the diverse philosophical approaches that underlie the different streams. We will briefly describe these positions. However, we would first warn that none of the different views described below appear in "pure" form in any of the authors cited. In some cases, there is a predominance of one over the others, although a combination of different elements from more than one theoretical basis is more common.

When we talk about philosophical approaches, we do not necessarily refer to direct quotations from actual philosophers. Admittedly, the literature reviewed here includes references to Plato, Aristotle, Descartes, Heidegger, Marx, Ortega y Gasset, Habermas and Rorty (Akbar, 2003; Blackler, 1995; Cook and Brown, 1999; Gueldenberg and Helting, 2007; Kolb and Kolb, 2005; Menger, 1999; Miller, 2008; Nonaka, 1994; Raelin, 1997; Sandberg and Pinnington, 2009; Spender, 2008; Spender and Scherer, 2007; Tsoukas, 1996), but this is not usual practice. The notable exception is Polanyi, who is extensively referred to (Brown and Duguid, 1991, 2001; Coff et al., 2006; Cook and Brown, 1999; Dyck et al., 2005; Easterby-Smith and Lyles, 2003; Gueldenberg and Helting, 2007; Hazlett et al., 2005; Ma and Yu, 2010; March, 1991; Miller, 2008; Nonaka, 1994; Nonaka et al., 2006; Raelin, 1997; Sandberg and Pinnington, 2009; Spender, 2008; Spender and Scherer, 2007; Tsoukas, 1996), and whose contribution has already been commented.

More often, basic philosophical notions are mediated by other disciplines, such as sociology, economic theory and psychology. Thus, Dewey (Cohen and Bacdayan, 1994; Cook and Brown, 1999; Easterby-Smith and Lyles, 2003; Kolb and Kolb, 2005; Miller, 2008; Nicolini and Meznar, 1995; Raelin, 1997; Spender, 1996, 2008; Spender and Scherer, 2007; Tsoukas, 1996; van der Sluis et al., 2002), Vygotsky (Brown and Duguid, 2001; Cheetham and Chivers, 2001; Kolb and Kolb, 2005; Raelin, 1997; Spender, 2008; Wenger, 1998), Skinner (Cheetham and Chivers, 2001; Shrivastava, 1983), and Bandura (Conger and Kanungo, 1988; Cheetham and Chivers, 2001; Libby and Tan, 1994; Morris and Moore, 2000; Raelin, 1997; Sims, 1983; Wenger, 1998; Wood and Bandura, 1989) appear cited. However, in most cases, the influence of these and other authors can be detected as underlying the different approaches taken by authors to learning. We will divide these authors into different groups.

First of all, we can find authors who receive the influence of economic theory, mainly supporting the neoclassic model. These authors talk about learning curves, learning by doing, and learning by experience as synonyms, and belong, mainly, to the OL field. The learning curve is the mathematical expression of the fact that production costs decrease over time, which implies that there has been a learning-by-doing. The concept of learning by experience 
suggests the idea of acquisition of experience through repetition, and also the concept of feedback, and thus, these models couple very naturally with behavioural models, as Tsoukas (1996) remarks. Typical of economic models and related to learning curves is the focus on cost calculation, resource allocation, and goals and alternatives, in addition to the postulates of economic individualism, with its introduction of a human agency theory based on the pursuit of profit maximization and individual self-interest (Cyert and March, 1963; Eisenstein and Hutchinson, 2006; Simon, 1991). These theories have been applied to different areas, such as training costs (Gattiker, 1995; Killingsworth, 1982; Mincer, 1962) and new technology application and transfer (Epple et al., 1991; Jovanovic and Nyarko, 1996), or have been harmonised with other complementary insights, making room for learning from others, or experimentation and invention (Foster and Rosenzweig, 1995; Grossman et al., 1977; Young, 1993).

The main criticisms of this view have focused on the narrowness of the notions of profit maximization and rational choice, and the disregard for environmental factors, which may ask for behaviours that go beyond a gradual adjustment by trial and error (Cangelosi and Dill, 1965; Levitt and March, 1988; Pisano, 1994).

Parallel to the theories described above, the evolution of psychology during the $20^{\text {th }}$ century has had a strong influence on different streams of management literature. Many authors from Spender (2008) back to Fiol and Lyles (Fiol and Lyles, 1985) note that psychology influenced the conceptualization of learning in both management and organizational theories through two main branches: behavioural psychology and cognitive psychology.

Behavioural psychology introduced the stimulus-response model which was applied both to the individual and to the organization under different forms. We have already mentioned how this model matches those coming from neoclassic economic theory. In addition, it is not difficult to see the link between this view and theories that envisage learning as an adaptation to the environment (i.e., response to environmental stimuli/feedback) and as the institution of routines (reiterated actions based on previous stimulus-response-feedback cycles). Both notions appear in OL literature (Cangelosi and Dill, 1965; Cohen and Bacdayan, 1994; Herriott et al., 1985; Levinthal and March, 1993; Levitt and March, 1988). The model was also applied to individuals - as was originally intended - by other authors (Akbar, 2003; Bonner and Walker, 1994; Sims, 1983; van der Sluis et al., 2002).

Behaviourism was mainly criticised for being simplistic and conveying a passive view of learning (Cook and Yanow, 1993; Dodgson, 1993; Nonaka, 1994; Spender, 2008; Spender and Scherer, 2007; Torbert, 1994; Wenger, 1998). Another critique comes precisely from cognitive psychology: "In contrast to behaviourism, with its concentration on inputs and outputs, cognitive approaches are more concerned with what goes on between these two stages, [...] the mental processes". (Cheetham and Chivers, 2001, p. 251)

Cognitive psychology influenced managerial and organizational literature by focusing on these processes. A great number of different approaches lay under this umbrella. We only will name connectionism and Gestalt psychology. Connectionist approaches are a constellation of different branches of cognitive psychology that are characterized by focusing on neurological and artificial intelligence studies. Their insights were applied to OL by taking the human brain or mind and/or computers as a model or metaphor for organizations' internal functioning (Tsoukas, 1996; Weick and Roberts, 1993). The emphasis of some authors on information, data and the role of IT systems in learning inside organizations (Alavi and Leidner, 2001; Coff et al., 2006; Davenport et al., 1998; Macdonald, 1995; Stein and Zwass, 1995) can be related to 
connectionism. As for the Gestalt school, according to Cheetham and Chivers (2001, p. 251), it "views consciousness as involving organised structures, patterns and configurations, and learning as a holistic process that cannot meaningfully be broken down into constituent parts, even for purpose of analysis." Polanyi (1966) himself conceived his proposal as a completion of the Gestalt theory. The influence of this school can be found in the scholars who attach great importance to shared beliefs, common interpretations and underlying assumptions for learning processes (Argyris, 1976; Argyris and Schön, 1978; Brown and Duguid, 1991, 2001; Cook and Yanow, 1993; Daft and Weick, 1984; Weick and Roberts, 1993). It also appears in authors who focus on learning styles, and internal knowledge processes - either in the individual or in the organization (King and Ranft, 2001; Kolb and Kolb, 2005; Macdonald, 1995; Maritan and Brush, 2003; Nonaka, 1994; Tan and Libby, 1997). We argue that the division of KM literature into "computational" and "organic" by some authors responds to some extent to the internal division of the cognitive view (Argote, 2005; Hazlett et al., 2005).

Connectionist approaches have been accused of disregarding emotions and motivational issues (Weick and Roberts, 1993; Wood and Bandura, 1989). Positivists have criticised the difficulty of operationalizing and, thus, empirically testing cognitive models. Cheetham and Chivers (2001) further develop this difficulty in the interpretation of tests as those problems originated from self-reporting and those relating to the universalization of findings. Spender (2008) warns of the risks of subjectivism and relativism entailed by cognitive approaches.

Lastly, we have another three distinct influences - pragmatism, social psychology and constructivism - that share in common their rejection of what they consider to be rationalistic stances, which they find in rational economic, behavioural and cognitive views, and which they consider to project a mechanistic and static picture of learning. These three approaches overlap in different authors, and for brevity we only can provide here a few examples of each.

Pragmatism manifests itself in the authors that focus on practice or work as the locus of learning (King and Ranft, 2001; Sandberg and Pinnington, 2009). Some authors propose shifting from knowledge to knowing (Blackler, 1995; Cook and Brown, 1999; Lave and Wenger, 1991; Tsoukas, 1996; Wenger, 1998). For example, Cook and Brown (1999) explicitly refer to Dewey and use the notion of "productive inquiry" to characterize this knowing in action. They propose an "epistemology of practice" that complements previous contributions, all of them considered as "epistemology of possession". This practice-focused perspective appears also in Brown and Duguid's (1991; 2001) papers about communities of practice (see also Wenger, 1998). The pragmatic view can be found wanting of cognitive foundations - i.e., it does not explain the role "that individual and collective cognitive frameworks or schemata play" "in the reproduction and potential transformation of practice" (Marshall, 2008, p. 414) - and also it is very difficult to operationalize. For constructivists, Deweyan pragmatism is still too "realistic", for it is still based on a search for "truth", in this case, a truth that resides in social interactions and practice (Spender, 2008).

Contributions from social psychology come mainly though Bandura, Dewey and other authors who see "learning as a continuous, dynamic and reciprocal interaction between individuals affecting, in particular, their attributes, values and behaviours" (Cheetham and Chivers, 2001, p. 253, emphasis in original). Wenger (1998) considers that Bandura's main contribution is in the imitation or modelling processes in the area of learning. Authors focusing on issues such as self-efficacy, empowerment, or mentorship (Armstrong et al., 2002; Conger and Kanungo, 1988; Hunt and Michael, 1983; Wood and Bandura, 1989) connect with this stream, but there are many other scholars who pay attention to social interaction as a means for learning (Argyris and Schön, 1978; Blackler, 1995; Brown and Duguid, 1991, 2001; Cook and Brown, 
1999; Cook and Yanow, 1993; Daft and Weick, 1984; Foster and Rosenzweig, 1995; Inkpen and Crossan, 1995; Kolb and Kolb, 2005; Lave and Wenger, 1991; Macdonald, 1995; Nonaka, 1994; Nonaka et al., 2006; Tsoukas, 1996; Wenger, 1998). As can be seen, most of these authors belong to the OL field, and this is natural, given that the organizational perspective is linked to the social perspective. In some extreme cases, individuals' judgment becomes a function of the social background, in other words, it is the organization or social network that learns, and the individual only learns through it (Tsoukas, 1996; Weick and Roberts, 1993). With Dodgson (1993), we could argue that social deterministic positions lose sight of the relevance of individual human agency, thus leaving an important aspect of the phenomenon outside the scope of the search. A simple example he provides is the expert or key employee who leaves the organization taking his or her knowledge with him or her.

Finally, we have constructivism. Cheetham and Chivers (2001) describe constructivism as a psychological perspective that envisions knowledge as an individual process by which each one builds their own way of making sense of the world. Philosophical foundations can be traced to Dewey, Marx, Vygotsky and Rorty, authors who are expressly cited in some cases (Blackler, 1995; Easterby-Smith and Lyles, 2003; Spender, 2008; Tsoukas, 1996). Very often, this constructivism is of a social nature, which signifies that meaning is socially constructed. In general, scholars stressing 'knowledge creation' over 'learning' follow in some degree the postulates of constructivism (Brown and Duguid, 1991; Cook and Brown, 1999; Kolb and Kolb, 2005; Marshall, 2008; Nicolini and Meznar, 1995; Nonaka, 1994; Nonaka et al., 2006; Spender, 2008; Spender and Scherer, 2007; Tsoukas, 1996; Wenger, 1998). Social constructivism conveys a very much fluid conception of learning in which the individual, or the organization, chooses each time anew the frameworks from which to act, which means that "a norm is always applied for 'another first time'." (Marshall, 2008, p. 421) Situations are always provisional and never pre-determined, it is the agent - or the community - who determines them by choosing the norms to be enacted, thus creating the context. Most radical constructivist approaches deny any kind of 'essences' or 'reality', making everything depend on interpretation (Spender, 2008; Tsoukas, 1996). But these positions - which represent the latest step in the rejection of any form of 'rationality - reveal themselves to be far from practicable when confronted with everyday managerial reality.

There is no space here to address all the problems presented by constructivism. Experiments in the area of collaborative learning have showed that 'pure' constructivism is impossible if any learning is intended: some form of knowledge base or feedback is needed (Yew and Schmidt, 2009). On the other hand, the critique that constructivism addresses to rationalism is unjustifiably extended to almost any other proposal that is not constructivism itself, which ends up falling into a sort of irrationalism. In this paper, we would suggest a revision of Polanyi's proposal as an interesting case. As Amartya Sen points out in the foreword of the 2009 edition of The Tacit Dimension, Polanyi's originality may be due to his maturing into philosophy from a different background, which enabled him to provide a view free of prejudices (Polanyi and Sen, 2009). Polanyi's position presents an unusual balance between the search for a universal truth of rationalism and the universal scepticism of postmodern constructivism. His rejection of positivism simultaneously championing commitment with truth sets an interesting precedent. In any case, a new review of the history of Western thought in search for additional options of rationality, truth and knowledge would be highly advisable. But this is a philosophical task.

After this introduction, in which we have presented the scope of the task and discussed basic conceptual issues, we will proceed to search for the contributions that different branches of managerial and organizational literature have made to the issue of learning. As has become 
clear in the last subsection, proposals can be very diverse and even contradictory to each other, but it is our intention to establish a dialogue that is as inclusive as possible with the different authors. We hope to establish a certain harmony among the different voices.

The next three sections will tackle, respectively, the antecedents of and conditions for practical learning, a review of the different proposals regarding learning in practice, and the obstacles to learning.

\section{Antecedents and Conditions of Practical Learning}

Learning in practice is a particular kind of activity that requires certain prior and concomitant conditions for it to take place. Van der Sluis et al (2002) characterize managers' on-the job learning as a combination of learning opportunities and learning behaviour. We will now focus on the first; the second will be the subject of the next section.

In our search for an outline that could help put order in the diverse approaches, we found Salas and Cannon-Bowers' (2001) literature review on training to be very useful. In this paper, after examining the literature on training needs, they focus on antecedent training conditions, which they divide into individual characteristics - including cognitive ability, self-efficacy, and goal orientation -, training motivation, and training induction and pre-training environment. We have broadened the perspective to practical learning in general and we have used the same schema. One last caveat is that, although we are talking about prior conditions, it is implicit that these conditions must remain present over the whole learning process.

\section{Particular Characteristics of the Learner}

Paraphrasing Salas and Cannon-Bowers' (2001) cited work, we could define these characteristics as 'what learners bring to the learning setting'. And what are they? Cognitive ability, goal orientations and expectations, a certain degree of self-efficacy, and, finally, other personal characteristics that add to the learning process. Both four elements are closely interrelated and mutually dependent.

Cognitive ability is quite a wide term, which actually may be understood in different ways.

For example, we have Cohen and Levinthal's (1990) absorptive capacity. Applied to organizations, it is "the ability of a firm to recognize the value of new, external information, assimilate it, and apply it to commercial ends" (p. 128). Cohen and Levinthal acknowledge the origin of this concept in cognitive and behavioural sciences at the individual level, which show that "accumulated prior knowledge increases both the ability to put new knowledge into memory, what we would refer to as the acquisition of knowledge, and the ability to recall and use it” (p. 129), and that prior possession of relevant knowledge and skill is the source of creativity. There are other elements of interest in this proposal: first, "learning is cumulative, and learning performance is greatest when the object of learning is related to what is already known" (Cohen and Levinthal, 1990, p. 131). This produces only incremental learning. Second, knowledge diversity may facilitate searching for information related to what is already known and, at the same time, enable "the individual to make novel associations and linkages" (ibid.).

Cohen - now with Bacdayan - contributes another related concept that is borrowed from human psychology and applied to organizations: procedural memory (Cohen and Bacdayan, 1994). "It is memory for how things are done that is relatively automatic and inarticulate, and 
it encompasses cognitive as well as motor activities" (p. 554) or "the form that stores the components of individual skilled actions - for both motor and cognitive skills” (p. 557), and they relate it to skills and habits (i.e., routines in organizations). It is a kind of memory that has a low decay rate, and it accounts for e.g., "the commonplace claim that "you never forget how to ride a bicycle"” (p. 557) and, we could add, the difficulty of changing - unlearning - certain ways of doing things that have become fixed after prolonged practice. What a person has already stored in this type of memory has an effect on what is consequently learned.

Related to these issues, Argyris (1976) discusses the two variables that can be altered to increase learning effectiveness, namely, the quality of information available and "receptivity to corrective feedback of the decision-making unit - that is, individual, group, or organization" (p. 365, emphasis added).

Kolb and Kolb (2005) propose a model of experiential learning based on learning styles. "The concept of learning style describes individual differences in learning based on the learner's preference for employing different phases of the learning cycle" (p. 195). Learning styles are due to a combination of genetics, life experiences, previous education and work and environmental demands. Sims (1983) elaborates an application of Kolb and Kolb's model to assess the personal competences-job requirements fit. Armstrong et al. (2002) consider them determinant in choosing the most suitable mentor.

Eisenstein and Hutchinson (2006) introduce a mathematical model in that "the market environment creates 'decision tasks' that are defined in terms of possible actions. These tasks evoke different decision-maker goals; in turn, goals differentially affect attention to stimuli, and differences in attention determine what is learned." (p. 245). Learners focus their attention on a specific range of outcomes called attention band, which is crucial for learning. Goals and expectations will be discussed in short. Although from a very different tradition, Weick and Roberts (1993) talk about the importance of heed in interactions to learn and prevent mistakes or accidents.

We could say, to conclude, that the literature dealing with core competences, knowledge base or expertise models (Argyris, 1976; Bonner and Lewis, 1990; Brown and Duguid, 1998; Coff et al., 2006; Fiol and Lyles, 1985; Inkpen and Crossan, 1995; King and Ranft, 2001; Lei et al., 1996; Libby and Tan, 1994; Pisano, 1994; Sandberg and Pinnington, 2009; Senge, 1990; Simonin, 1997; Tan and Libby, 1997; Torbert, 1994) is pointing at this same idea: learners acquire certain competences that make them able to learn more and more. In consequence, the degree of expertise that a learner already possesses will affect further learning. Experts have a more developed belief system and their ability to discriminate is greater than novices' (Inkpen and Crossan, 1995).

As we will see in the last subsection of the paper, there are some equivalent cognitive disabilities that play an opposite function as learning inhibitors.

Goal orientations and expectations are the second group of characteristics we will examine in our review.

Centrality of goals and expectations is clear in rational models such as the one presented by Arrow (1962), who explicitly identifies rational expectations with the state of 'perfect foresight' of outcome probability. In the early work of Cyert and March (1963), the pillars of their economic theory of decision are organizational goals, organizational expectations, organizational choice, and organizational control. It is noteworthy that, though they use the word 'organizational', their perspective is mainly that the organization is a coalition of individuals, who are actually those who have goals or expectations, on the basis of which they 
choose and organize control mechanisms. Eisenstein and Hutchinson (2006) is another example of these theories in which decision-making is linked to predictions and estimations regarding expected outcomes. They merge the economic rational model with a behaviorist approach in which mechanisms of reaction to error (due to feedback) register an increase of attention and are combined with a proactive increase of attention in areas detected as riskier. Their conclusion is that relying on experiential learning alone may be tricky because goals themselves may divert attention from informative stimuli, and therefore, "managers and consumers should increase their use of objective analyses and decrease reliance on experience or intuition" (Eisenstein and Hutchinson, 2006, p. 256).

According to Argyris and Schön (1978), it is the outcome-expectation mismatch that triggers correction in the form of modification of images, maps and activities in a learning loop. If it is feedback from experience that indicates whether success has been achieved, the definition of 'success' depends highly on - social or individual - expectations, to the point that the notion itself of 'success' is ambiguous (Alvesson, 1993; Levitt and March, 1988). Whether expectations are considered individual or social depends on the particular perspective that authors adopt regarding individuals and their relationship with the organization and broader environment in which they dwell. In turn, further expectations or goals adapt to results: success usually triggers higher expectations - in a curve that then decreases, due to self-complacency -, and failure lowers them (Herriott et al., 1985; Levinthal and March, 1993). The latter also note that, in addition to outcomes, "an actor's goals adapt to the mean performance of other actors as well as to her own performance" (Herriott et al., 1985, p. 300). Some consequences of these mechanisms will be addressed in the last section of the paper.

Nonaka (1994) highlights that introducing challenging goals is a way of generating intentional 'crisis' that will lead to 'creative chaos'. However, this practice will only be successful if agents have developed a reflective capacity. Otherwise, there is the risk of falling into 'destructive chaos.' Wood and Bandura (1989) also insist on the motivational function of goals - provided that they are not too distant - and warn that challenging goals may have no effect in a highly complex environment. Brown and Duguid (1998) note the relevance of goal-oriented planning even in organizations with a very fluid structure and especially in the so-called self-organizing systems. In his critique of the 'learning organization' concept, Coopey (1995) argues that leaving goals undefined under the pretence of flexibility is a way of keeping members of an organization subject to arbitrariness and, therefore, originating structures that prevent learning.

Salas and Cannon-Bowers (2001) mention self-efficacy as an important prior condition for learning. They define it as the belief that one can perform specific tasks and behaviours. It leads to better learning and performance, and it also mediates other factors as job satisfaction, organizational commitment, adjustment, motivation and the use of technologies.

This notion is combined with modelling mechanisms in the paper by Wood and Bandura (1989), in which they define self-efficacy as "people's beliefs in their capabilities to mobilize the motivation, cognitive resources, and courses of action needed to exercise control over events in their lives" (p. 364). Besides skills, it is the feeling of self-efficacy that affects motivation and, therefore, the efforts needed to perform a task (in this case, a learning practice). As sources of self-efficacy beliefs, they name mastery experiences, modelling, social persuasion, and physiological or emotional states. In their work, Wood and Bandura conclude that self-efficacy affects strategy setting and performance. 
Conger and Kanungo (1988) integrate the notions of self-efficacy and power to build the concept of empowerment. They define empowerment as "a process of enhancing feelings of self-efficacy among organizational members through the identification of conditions that foster powerlessness and through their removal by both formal organizational practices and informal techniques of providing efficacy information" (p. 474, emphasis in the original). It is noteworthy that they propose the possible negative effects, such as overconfidence, as a subject for further research. In a context of critique to the learning organization, Snell and Chack (1998) present a model to test empowerment through grass-roots members' participation in double-loop or triple-loop learning activities (i.e., activities that challenge the firm's fundamental assumptions or practices, and activities that show a mastery of learning mechanisms). It means the contrary to the passive acceptance of top-downward initiatives, and, hence, an active disposition to learning.

In addition to the factors provided by Salas and Cannon-Bowers (2001), we could include here other factors that are equally significant, but have been mentioned in few articles.

First of all, there are demographic characteristics (age, gender, race, level of formal education, economic situation, and work position). We have found them in some economic studies on training (Knoke and Kalleberg, 1994; Mincer, 1962; Salas and Cannon-Bowers, 2001) and in some papers on mentoring (Armstrong et al., 2002; Hunt and Michael, 1983). Personality traits are mentioned by Salas and Cannon-Bowers (2001). The relevance of position inside the firm has been underscored by Nonaka and colleagues (Nonaka, 1994; Nonaka et al., 2006), who assign a particular task to each level in the learning cycle. The above-mentioned paper by Snell and Chack (1998) also pays attention to hierarchical differences. Coopey (1995) refers to the division of the company in Machiavellian, manipulative managers and subordinate employees. Fiol and Lyles (1985) state that single-loop or lower-level learning (i.e., adjustments of procedures and routines by immediate feedback) is more characteristic of lower and middle levels of management, though not exclusive. ${ }^{2}$

\section{Environmental Conditions}

In the introduction we described the OL literature as being highly useful, besides other issues, for describing the environmental conditions of learning. The organization is the place where practical learning occurs, and this means that scholars who study learning in organizations and learning by organizations (Cook and Yanow, 1993) must have a lot to say about the environmental conditions of learning. This is especially true in the literature about the learning organization, where the characteristics that an organization must have for it and its members to learn are the main theme. Therefore, organizations must have a particular internal environment to foster learning and, in addition, there are factors external to the organization that influence learning.

A lot has been written about the conditions for internal organizational learning. We will only provide a few illuminating examples here, using some insights by Pedler et al. (1989).

Pedler et al.'s work is known as one of the first to talk about the learning organization. They consider their proposal as going beyond training (this is a notion they trace back to the 1960s and consider obsolete) and self-development (popular in the 1980s) towards the idea of simultaneously learning and working, evolving from "human resources" to "resourceful humans". We will summarize the organizational traits they propose in three: 1) resources for

\footnotetext{
${ }^{2}$ All these factors are given more attention in the HR management literature, which we are not including here for the reasons stated in the introduction.
} 
self-development must be available for all members, 2) the organization must be designed in a way that culture, internal policies and practices encourage and produce learning, and 3) information systems are widely used to support learning.

First, we will consider the availability of self-development resources for all. Managerial literature focuses on resources for managers. They encourage managers to develop a holistic vision of the organization, which would identify with higher learning stages (Senge, 1990; Spender, 1996; Torbert, 1994).

The second characteristic is that the cultural, political or governance structure, and the organization's practices encourage and produce learning. Redesigning organizations and their practices to facilitate learning is something the earlier works by Hedberg (1981) and Sims (1983) had already proposed as a theme for further development. It is commonly accepted that loose ties, organizational slack, fluid communication, and flat structures, as opposite to rigid, routine, hierarchical organizations, are the characteristics facilitating learning. De Geus (1988) talks about open systems in opposition to closed systems and autocratic organizations. The concept of 'psychological safety' - i.e., the feeling that disclosure and discussion of mistakes is not only admitted but viewed positively in the organization - points in the same direction (Cannon and Edmondson, 2005; Edmondson et al., 2001; Lee et al., 2004; Tucker and Edmondson, 2003) ${ }^{3}$. Snell and Chack (1998), Carroll (1998), Senge (1990), Shrivastava (1983) and Argyris (1976) also criticize authoritarian styles and encourage participative decisionmaking. Fiol and Lyles (1985) and Inkpen and Crossan (1995) deem the 'no learning-no change' situation to be typical of bureaucratic, mechanistic organizations. Brown and Duguid (1991; 2001) envision these organizations as large, ossified structures, compared with the fluidity and internal dynamism of the organizations which cultivate diversity through communities of practice, which cannot be supported through intrusive practices. Lei et al. (1996) remark the importance of internal communication. Similarly, Nonaka and colleagues (Nonaka, 1994; Nonaka et al., 2006) compare hierarchical organizations to "heterarchical" organizations, which possess enabling conditions such as self-organizing teams and knowledge activists. These organizations also possess diverse types of $b a$. This is a Japanese term that means shared space for emerging relationships. This concept is taken by Kolb and Kolb (2005) and combined with that of legitimate peripheral participation (i.e., the gradual incorporation of novices to a practice), originally coined by Lave and Wenger (1991). In Hackman and Wageman's (1995) review on Total Quality Management (TQM), they note that this management philosophy's emphasis on scientific knowledge, apparent encouragement of single-loop learning, and topdown distribution of authority and learning opportunities needs some changes if it is to avoid becoming a new version of old-time scientific management.

Apparently in contrast to what has been said, Cangelosi and Dill (1965) consider that different types of environmental stress work as learning stimulators, because the trigger to learn is the perceived imbalance between outcomes and expectations. These are discomfort stress - caused by environmental uncertainty -, performance stress - uncertainty about the outcome; it is the main factor, and reinforced by previous experience - and disjunctive stress - caused by the

\footnotetext{
${ }^{3}$ Interestingly, Cheetham and Chivers (2001) remark that there is a distinction between psychologically safe - which they call blame-free - environments and consequence-free environments. In the first, mistakes are given attention and considered as a source of learning; the second, on the contrary, does not conduce to learning because mistakes are dismissed as having no importance.
} 
tension between individuals and sub-groups. They also acknowledge that there are (variable) thresholds of stress.

The third of the characteristics envisioned by Pedler et al. (1989) which we will discuss here is the use of IT systems. It is noteworthy that, after the emphasis on information management and the use of IT typical of the 1980s (Nonaka et al., 2006), literature has reached a more balanced position: these systems are, above all, a support for learning, and never a substitute (Beamish and Armistead, 2001; Hansen et al., 1999; Huber, 1991; Levitt and March, 1988; Stein and Zwass, 1995). For some kinds of learning - i.e., more practical kinds -, face-to-face interactions are necessary (Cook and Yanow, 1993; Davenport et al., 1998; Hansen et al., 1999). This matter will be addressed again at the end of the next section.

It is important to point out that these characteristics do have a dark side. First of all, as Morris and Moore (2000) note, forceful introduction of learning mechanisms may not have the desired effect: there are learning systems that contain forms of threatening accountability, such as excessive monitoring, control and punishments. On the other hand, there is the possibility, Coopey (1995) argues in his critique to Senge (1990) and Pedler et al. (1989), that the so-called 'learning organization' could become a cover and persuasion tool used by managers and key members to perpetuate their domination over the rest of the organization. We agree that what Hedberg (1981) calls the "good and orderly organization" may simply be a utopia or that, in the hypothetic case that it existed, it would risk dying of success. Hedberg's proposal is an interesting one: the properties of this ideal organization - consensus, contentment, affluence, faith, consistency and rationality - should exist in "minimal amounts - that is, just a little bit more than not enough (...) This would provide for enough triggering, reasonably easy unlearning, sufficiently low trust in previous successes, and enough slack resources to implement new strategies" (Hedberg, 1981, p. 22).

Pedler et al. (1989) argue that a learning organization has members - "environmental scanners" - who provide the organization with external knowledge and this organization exchanges information with other organizations. That means that the state of external environment is also important for both learning by the organization and its members.

Competitors are an important factor, underlined by the OL authors who focus on knowledge spillovers - i.e., knowledge of external precedence that has 'leaked' in some way or that is easily capturable (Argote, 2005; Cohen and Levinthal, 1990; Foster and Rosenzweig, 1995) and learning from others (vicarious learning) (Argote, 2005; Baum and Dahlin, 2007; Cheetham and Chivers, 2001; Hedberg, 1981; Huber, 1991; Lei et al., 1996; Levitt and March, 1988; Morris and Moore, 2000; Shrivastava, 1983; Stein and Zwass, 1995; Wood and Bandura, 1989). On the other hand, Brown and Duguid (2001) have highlighted the importance of taking into account that, just as there are communities of practice inside the organization that account for certain knowledge flows, there are other trans-organizational communities of practice. These are composed of members of a same - professional or occupational - practice who work in different organizations and who are responsible for knowledge flows from and to the external environment (see also Brown and Duguid, 1998). Joint ventures and similar collaborative experiences are other ways of accessing external knowledge (Inkpen and Crossan, 1995; Macdonald, 1995; Simonin, 1997). March (1991) refers to an ecology of competition in which "learning that increases the mean always pays off" with a small number of competitors, but if there are many competitors, increases in the variance make the difference (p. 82). On the other hand, there is also value in knowledge coming from sources external to the industry, because it may provide new and unexplored insights (Cohen and Levinthal, 1990). 
Political and social context also play an important role, as well as the general social knowledge base, which includes the degree of technological development in the society to which organizations and learners dwell (Brown and Duguid, 1998; Lave and Wenger, 1991; Levinthal and March, 1993; Miller, 2008; Pisano, 1994; Soo et al., 2002).

In general, there is agreement that an excessively turbulent environment does not facilitate learning; on the other hand, too little turbulence leads to self-complacency (Cohen and Levinthal, 1990; Fiol and Lyles, 1985; Hedberg, 1981; Inkpen and Crossan, 1995; Lei et al., 1996; Levinthal and March, 1993; March, 1991). How much turbulence is tolerable depends, again, on the particular characteristics of the learner, which have been commented above and which enable learners not only to tolerate pressure but also to gain benefit from difficult environments (Hedberg, 1981; Lei et al., 1996; Nonaka, 1994). On the other hand, states of turbulence or calm are not the only way to analyze the external environment; it can be also complex or simple and benevolent or hostile (Hedberg, 1981).

\section{Motivational Aspects}

The subsection devoted to motivational aspects will be brief. Paraphrasing Salas and CannonBowers (2001, p. 479), we could define learning motivation as "the direction, effort, intensity, and persistence that individuals or groups apply to learning-oriented activities". They also state that motivation is influenced both by individual and environmental characteristics. The concepts discussed above of 'empowerment', 'self-efficacy', 'levels of stress', an encouraging 'organizational culture', 'environmental turbulence' or 'psychological safety' are clear examples of mechanisms that have a clear influence on learning motivation.

Motivation is included within learning facilitators in many cases (Alavi and Leidner, 2001; Cyert and March, 1963; Davenport et al., 1998; Lave and Wenger, 1991; Salas and CannonBowers, 2001; Stein and Zwass, 1995; Wood and Bandura, 1989), although the matter is addressed in depth in only a few of them. For example, Wood and Bandura (1989) argue that self-motivation mechanisms operate partly through people's internal standards and evaluations. That means that self-satisfaction, self-reaction and self-evaluation function together. Selfefficacy adds a judgment about the results of self-evaluation, in particular, whether these results are encouraging with respect to a particular action. They add that goals are also highly motivational because they provide a sense of purpose.

In their review of TQM, Hackman and Wageman (1995) state that there are three kinds of motivation: intrinsic motivation - for the sake of growing or developing oneself -, task motivation - good feeling of achievement in a task -, and social motivation - incentives intrinsic to cooperating with others and being recognized by others. They underscore that many TQM projects rely solely on intrinsic motivation. There is a long-standing controversy between the advocates of intrinsic motivation and those of extrinsic motivation (i.e., motivation based on benefits granted by a source external to the agent). This controversy is closely linked to the role of incentives and compensation systems to enhance learning (Alavi and Leidner, 2001; Cangelosi and Dill, 1965; Cohen and Bacdayan, 1994; Cohen and Levinthal, 1990; Conger and Kanungo, 1988; Coopey, 1995; Davenport et al., 1998; Gattiker, 1995; Hackman and Wageman, 1995; Hedberg, 1981; Levinthal and March, 1993; Pedler et al., 1989; Snell and Chak, 1998; Stein and Zwass, 1995; Wood and Bandura, 1989; Young, 1993). Under the economic perspective, some authors understand these incentives to be economic investments (Gattiker, 1995; Young, 1993), while others acknowledge the existence of non-financial benefits (Coff et 
al., 2006), especially those under the category of social rewards or incentives (Cohen and Levinthal, 1990; Hackman and Wageman, 1995; Wood and Bandura, 1989).

Regarding this subject, Wood and Bandura (1989, p. 376) argue that, in some cases, "external motivators, such as incentives or assigned goals, can undermine [employee's] performance by diverting their attention from how to best perform the task to concerns about the consequences of failure." Something similar is sustained by Levinthal and March (1993) when they tackle the role of incentives in economic theory. In their typical style, Spender and Scherer (2007, p. 18) criticise agency theory in its use of the simplistic policy of incentives and punishments for being "a narrow theory in that imagination is admitted but subordinated to reason." On the contrary, we have scholars who formally defend instituted rewards or compensations as fostering learning, e.g., using IT or other systems for information sharing (Davenport et al., 1998; Gallupe, 2001; Soo et al., 2002; Stein and Zwass, 1995). Regarding this subject, Lave and Wenger (1991) warn that this kind of directly sought motivation is quite different from that which naturally emerges in 'legitimate peripheral participation' processes. Hackman and Wageman (1995) propose a combination between extrinsic and intrinsic motivation.

In any case, motivational practices must be appropriate to the organization, they "should be long term and should tie in with the general evaluation and compensation structure" (Davenport et al., 1998, p. 54). When it comes to applying theoretical principles to practice, it is worth pointing out that there are several approaches that some authors have considered to be incomplete, precisely because they ignore or do not give a good account of motivational aspects. These are some behavioural models (Cheetham and Chivers, 2001) and biological or cognitive models (Penrose, 1959; Weick and Roberts, 1993; Wood and Bandura, 1989).

As can be seen, the literature reviewed here provides interesting insights about the many aspects of the learner's starting-point situation that must be taken into account. Let us move now to the learning process itself.

\section{Different Approaches to Learning in Practice}

We will very roughly follow here the outline of Cheetham and Chivers' (2001) literature review on how professionals learn in practice. They divide this literature into three groups that could be conceived as concentric circles: 1) general theories of development, 2) theories of adult development, and 3) some practical techniques and supporting concepts of professional development. Number 1) would correspond to what has been described in the introduction as different theoretical bases for learning. Now we will integrate some ideas of what Cheetham and Chivers propose in 2) and 3). Once more, we caution that it is not our intention to make an exhaustive collection and classification of all the techniques that are being applied in practice but to show how different approaches to learning in practice have produced different applications in the management field.

In particular, we will deal with models of work-based learning (i.e., hands-on approaches). Secondly, we will pay attention to models focusing on learning from others and imitation (e.g., vicarious learning or modelling). Finally, we will explore other proposals that stress professional development towards expertise. This section will conclude with some considerations about the function of different support tools such as instruction, coaching and IT systems and new technologies. 
Once again, it is possible that there are overlaps within the different subsections, but we have tried to reflect the predominant focal point in each proposal.

\section{Learning in Practice or Work-Based Learning: Hands-on Approaches}

In this subsection, we will review diverse proposals regarding what we could generically call learning in practice, i.e., learning that takes place in the actual job practice. This can be given different names, depending on the aspect that is considered pivotal; thus, we talk about workbased learning, on-the-job training, learning-by-doing, legitimate peripheral participation and so on. This learning may be sought through formal mechanisms specifically designed for this purpose or, on the contrary, it may be the fruit of informal interactions. When we talked about internal organizational conditions for learning we already addressed this distinction: although it is important that the organization designs formal learning mechanisms, it must avoid rigidity and an excess of control. It seems that the best alternative is the combination of both formal and informal mechanisms. For instance, Nonaka (1994, p. 17) aims for this balance by advising that "the potential contribution of informal groups to organizational knowledge creation should be related to more formal notions of a hierarchical structure." Even authors strongly supporting informal knowledge-sharing acknowledge the need for organizations to coordinate it through negotiation, and to seek ways to counteract its potential negative effects (Brown and Duguid, 2001; Macdonald, 1995).

We will examine basically three groups of scholars: 1) those focusing on the concept of practice itself, 2) those exploring the idea of experience, and 3) scholars who directly address on-the-job training.

\section{Learning and Practice}

If we go back to the different theoretical bases described in the introduction, we can find there the groups of authors who devote their efforts to work practice itself as a learning activity. The sources of their approaches can be traced back to pragmatism, social psychology and constructivism, combined in different ways. All of them share 1) an eminently proactive conception of learning, 2) the idea that learning is the adoption of certain skills and/or mental models or beliefs, 3) the notion that practical learning is, at the same time, shaping their own identities, 4) all envisioned as a dynamic process 5) that occurs within social interaction. All of these characteristics can be found to varying degrees in the proposals we will comment on next.

First of all, we could mention the influential notion of communities of practice, which was introduced by Brown and Duguid (1991), and which names those networks or communities of members of an organization who share the same practices. The same authors later extended this concept to trans-organizational communities of practice (Brown and Duguid, 2001), when they realized that members of organizations share knowledge with other practitioners who belong to the same professional category or perform similar tasks in other organizations. Nonaka (1994) draws from this concept to explain self-organizing teams, which have the function of fostering creativity within the organization. Lave and Wenger $(1991)^{4}$, and later Wenger (1998) also refer to communities of practice, but they focus on how one becomes member of such a community,

\footnotetext{
${ }^{4}$ Interestingly, Lave and Wenger (1991) provide some examples in which there is practical learning but not necessarily by doing: Yucatan's apprentices learn to become midwives by accompanying their masters, observing and performing peripheral tasks; Alcoholics Anonymous learn through verbal interaction.
}

16 - IESE Business School-University of Navarra 
that is, through a process of legitimate peripheral participation: newcomers "learn by taking up a position on the periphery of skilled practice and being allowed (hence the importance of legitimacy) to move slowly from the periphery into the community and the practice involved" (Brown and Duguid, 1998, p. 107) as they gain expertise. Weick and Roberts (1993) introduce the concept of collective mind and explain how it is constantly shaped through the interaction between newcomers and seniors. Similar ideas appear in Cook and Brown's (1999) work: they explain how knowledge emerges through social interaction and interaction with things in what they call a generative dance.

Another practice-focused approach is that of Cohen. As mentioned in the previous section, he studies absorptive capacity (Cohen and Levinthal, 1990) and procedural memory (Cohen and Bacdayan, 1994) as mechanisms that function in practical learning. Raelin (1997) combines many of these ideas in his model of work-based learning, which is enriched with the acknowledgement of the respective roles played by reflection and theoretical knowledge (in the form of applied science). More in the epistemological area, Miller's (2008) interpretation of Polanyi's works on tacit knowledge also points at the pragmatic foundation of some of Polanyi's proposals. Miller highlights that skilful performance which involves physical - or bodily - activity is the proof that a wholly explicit knowledge is unthinkable. In other words, "[p]ractices always have performative aspects that go beyond what is codified in organizations" (Miller, 2008, p. 945). Related to this, King and Ranft (2001) focus on knowing through action and improvisation based on research on the surgery certification process.

Lastly, we can mention other authors who follow a more radical social constructivist stream in which practitioners are constantly re-creating meaning, context and their identities through practice (Blackler, 1995; Lave and Wenger, 1991; Nicolini and Meznar, 1995; Spender, 1996, 2008; Spender and Scherer, 2007; Tsoukas, 1996). Kolb and Kolb's (2005) learning styles model is also based on a social constructivist conception of learning.

\section{Learning and experience}

Notwithstanding the obvious connection between "practice" and "experience" in ordinary language, in managerial and organizational literature these two concepts draw from different streams and traditions. In the case of learning from experience, the roots are clearly behaviourism, and also economic theory (i.e., learning-by-doing models) plays an important role.

In fact, a first approach to the expression "learning from experience" leads us to the economic literature on "learning curves" and "learning-by-doing". But this view reduces learning to trialerror processes and the analysis of input-output economic parameters, which is reminiscent of repetition, automatism and gradualness. Therefore, this basic schema has been enriched with other insights (Argyris, 1976; Argyris and Schön, 1978; Baum and Dahlin, 2007; Epple et al., 1991; Herriott et al., 1985; Levinthal and March, 1993; Levitt and March, 1988; Wood and Bandura, 1989). Some authors, such as Kolb and Kolb (2005), Huber (1991) or Herriott et al. (1985), prefer to talk about "experiential learning". In any case, the concept of "experience" conveys a dynamic notion in which 1) learning is understood to be the result of problemsolving attempts, 2) feedback from the outcomes - both positive and negative - leads to learning (adaptation), 3) therefore, experience is enriched over time in a continuous cycle: learning by experience is cumulative (learning-by-doing).

An influential model belonging to this group is that of Argyris' (1976; Argyris and Schön, 1978). Learning is understood as the "detection and correction of errors, and error as any feature of 
knowledge or of knowing that makes action ineffective" (Argyris, 1976, p. 365). Thus, he distinguishes between single-loop learning, double-loop learning and deutero-learning. The first loop includes corrective actions to solve immediate problems within accepted routines; the second is linked to corrective actions involving modification of underlying norms, policies and objectives (i.e., theories of action); deutero-learning means learning how to carry out single-loop learning in double-loop learning (i.e., learning to learn, or meta-learning). This model is later applied to organizations by Argyris and Schön (1978) and it has been adopted by many scholars. For instance, Hedberg (1981) and Fiol and Lyles (1985) talk about lower-level and higher-level learning, which are respectively defined by the latter as the "development of some rudimentary association of behavior and outcomes" (p. 807) and "adjusting overall rules and norms" (p. 808) (see also Torbert, 1994). In both forms, the model has become very popular in management literature because of its clear practical implications: it is by far more difficult to achieve doubleloop learning than single-loop learning, but it may be the only way to solve complex problems, or simple problems that may have serious consequences or become eternalized. ${ }^{5}$

Another stream sourcing from the concept of experience is that of learning as adaptation. Behaviour is constantly adapting to previous feedback, and therefore, to how environment is perceived. Imbalance between expectations and outcomes is considered to be the trigger for learning, both by individual-focused authors and by OL scholars (Argyris, 1976; Cangelosi and Dill, 1965; Cyert and March, 1963; Herriott et al., 1985; Levinthal and March, 1993; Levitt and March, 1988; March, 1991; Simon, 1991). Some of these authors enrich this view, which may seem quite passive, with new insights. Cangelosi and Dill (1965) highlight the influence that relationships between individuals and sub-groups have in the organization in the form of conflicts and tensions. Others introduce notions such as "mutual learning", "ecology of learning" or "ecology of competition", all of them stressing the interdependence of experience and how learners compete for resources (Herriott et al., 1985; Levinthal and March, 1993; Levitt and March, 1988; March, 1991).

In the educational field, Kolb and Kolb's (2005) model of experiential learning merges the basic behaviourist experience-learning-experience cycle with pragmatist (learning is knowledge creation through the transformation of experience), cognitive (reflection and abstraction are present) and other (legitimate peripheral participation, $b a$, ecology of learning, etc.) insights. Learning is conceived as a cycle or spiral that goes from concrete experience to reflective observation to abstract conceptualization to active experience and again to concrete experience. They argue that different learners prefer certain stages of the learning cycle and thus they propose a series of nine learning styles. Although the model has been criticised for being too simplistic and for the lack of theoretical support (Cheetham and Chivers, 2001), the merit of their contribution is their highlighting of the fact that different learners learn differently. The model has been applied in managerial literature (Raelin, 1997; Sims, 1983).

Finally, as a result of accumulation of experience, routines emerge. Cohen and Bacdayan (1994) prefer to talk about habits and skills for individuals and routines as their equivalent for organizations. As we will see in the subsection devoted to expertise and developmental models, habits and skills are to be seen mainly as capabilities, but, if understood as automatism, custom or consuetude - mere routine - they may lead to problems like self-complacency (competence traps), blindness in detecting mistakes and even inability to adapt to changes. All these negative

\footnotetext{
${ }^{5}$ For example, see Carroll's (1998) distinction between root errors and 'band aids' in high-hazard industries, and Tucker and Edmondson's (2003) first-order and second-order problem-solving in hospitals.
} 
effects will be tackled in the last section of this paper. In the OL field, other authors who recognize the existence of organizational patterns in the form of shared beliefs, shared practices and norms do not use the term "routines" and have replaced it by "culture" (Cook and Brown, 1999), "organizational mind" (Weick and Roberts, 1993), mental maps (Argyris and Schön, 1978; Hedberg, 1981; Marshall, 2008) and other equivalent terms. They consider the term "routines" too linked to traditional and mechanistic behavioural models, and they propose a more dynamic and creativity-focused concept of learning, always under a collective perspective.

It has been stated at the beginning that both positive and negative feedback lead to learning. We will now pay attention to learning from errors and quasi-errors (i.e., close calls).

Adaptive models, and in general, models of learning from experience consider previous errors as the spur of learning (Akbar, 2003; Argyris, 1976; Baum and Dahlin, 2007; Cangelosi and Dill, 1965; Cannon and Edmondson, 2005; Carroll, 1998; Eisenstein and Hutchinson, 2006; Levinthal and March, 1993; Levitt and March, 1988; Morris and Moore, 2000; Tucker and Edmondson, 2003). Given the amount of research supporting this idea, it is striking that most managerial and business literature directly addressed to practitioners focuses almost exclusively on personal and organizational success. There may be some obstacles to learning from mistakes, such as a culture that punishes disclosure of negative issues, lack of trust, unwillingness to face complex problems, or resistance to change (Cannon and Edmondson, 2005; Carroll, 1998; Davenport et al., 1998; Levinthal and March, 1993; Wood and Bandura, 1989). In addition, in their research on learning from train accidents, Baum and Dahlin (2007) conclude that, because of the implications mentioned above and the complex relationship between aspiration and performance, "learning from successful and failed operations may be fundamentally different" (p. 381). Cannon and Edmondson (2005) provide an interesting analysis of technical and social barriers to the activities - identifying failure, analyzing failure and deliberate experimentation - that lead to learning from failure (see also Tucker et al., 2002).

On the other hand, learning from quasi-errors implies stretching the learning-from-experience model beyond its boundaries. Indeed, it means learning not only from "what has been" but from "what might have been" (Morris and Moore, 2000). This requires the use of reasoning and imagination in order to construct hypothetical situations that are as rich as possible - in both better and worse scenarios - for instilling "performance-promoting lessons" (Morris and Moore, 2000, p. 739). This is called counterfactual thinking. Something similar can be done in highhazard settings, in which failure is very rare but has fatal consequences. According to March et al. (1991), lack of sample is compensated with 1) a richer analysis of actual history, in order to draw as much consequences as possible; 2) creating near-histories (imagining "what might have been"); 3) and constructing hypothetical histories and analyzing the potential consequences (see also Baum and Dahlin, 2007).

Up to now, the most common notion of experience - interacting with the environment in order to solve a problem and receiving a subsequent feedback that shapes future behaviour - has been discussed. There are other ways of learning that also include experience. One is collaborative learning; the other is experimentation, i.e., the use of simulation of real experience in order to learn.

Collaborative learning is a proposal typical to constructivism - a Vygotsky's contribution. The notion of collaboration suggests the need for social interaction but it is not to be mistaken for vicarious learning or learning from others, because collaborative learning does not consist of imitating others' behaviour but resides in the very interaction that makes learning emerge. "The 
key issue is whether each individual has actually learned more" (Cheetham and Chivers, 2001, pp. 262-263), although there will be more learning if the interaction is with knowledgeable individuals. Salas and Cannon-Bowers (2001) distinguish between collaborative protocols and team training because in the former "trainees are trained in groups, but not necessarily to perform a team task" (p. 482). The "generative dance" described by Cook and Brown (1999), and Weick and Roberts' (1993) "heedful interaction" follow this thread. There have been applications of collaborative learning to organizations, for example, in the context of joint ventures (Inkpen and Crossan, 1995; Macdonald, 1995) or team work for problem-solving or creativity purposes (Cook and Brown, 1999; Edmondson et al., 2003; Hackman and Wageman, 1995; Nonaka, 1994; Senge, 1990; Torbert, 1994). One conclusion would be that for any individual to learn, he or she must have or develop collaborative or social skills (Edmondson et al., 2001; King and Ranft, 2001; Simonin, 1997). Another is that constructivism only works if individuals in the group already possess some knowledge base, or if there is some expert or senior guiding the process. Otherwise, learning does not occur (Inkpen and Crossan, 1995; Yew and Schmidt, 2009). ${ }^{6}$ In other words, pure constructivism is not possible.

If learning from experience is related to learning-by-doing, Pisano (1994) characterizes learning from experiments as "learning-before-doing". Experiments always use some sort of simulation of reality in order to obtain experience without running risks. Individuals do often experiment: for example, consumers experiment with new products (Grossman et al., 1977), and farmers with new seeds and technologies (Foster and Rosenzweig, 1995), but experimentation is systematically undertaken in organizational settings. Thus, it is extensively studied in OL literature. Many companies create their RandD departments for learning purposes. ${ }^{7}$ Cohen and Levinthal (1990) deem these departments as proof that proactive firms do not wait for failure to learn. But, beyond RandD departments, there are some organizations that have an experimenting mindset (Hedberg, 1981; Huber, 1991). It seems something distinctive of Japanese firms (Dodgson, 1993; Inkpen and Crossan, 1995; Nonaka, 1994). Nonaka (1994) attributes it to a more hands-on approach to work - "on-the-spot-ism" - and a more holistic view of the interaction with the world in general - which he attributes to oriental culture -, that needs, however, to be counterbalanced with reflection. But experimentation is also cultivated in Western companies through diverse forms of simulation. We use here this term in a broad sense: human interactions can be simulated for learning purposes; new designs and many products can be tested in controlled settings - i.e., simulated contexts - with the aid of IT systems, machines and laboratories.

Simplified human relationships scenarios, such as games and role-playing are of common use, and they are particularly valuable because organizations do not have the resources or opportunities to experience a wide range of situations (Cangelosi and Dill, 1965; De Geus, 1988; Salas and Cannon-Bowers, 2001; Senge, 1990; Wood and Bandura, 1989). Schematic rules and impersonation of fake roles have the purpose of imitating real life and learning comes through this imitation. Their usefulness extends to research: indeed, many - perhaps, too many (Akbar, 2003; Argote and Greve, 2007; Hedberg, 1981; Wood and Bandura, 1989) - research studies on

\footnotetext{
${ }^{6}$ Yew and Schmidt's (2009) interesting work is based on a collaborative experiment with students. The transcriptions of the students' meetings and interchanges without the teacher being present are full of dead-end conjectures, and, sometimes, agreements on wrong assumptions. Similarly, Bonner and Walker (1994) reported in their research on auditors that practice without feedback resulted in no knowledge acquisition or, even, in the decrease of knowledge.

${ }^{7}$ Dodgson (1993) and Pisano (1994) even consider RetD departments to be the main source of learning in companies.
} 
learning base their empirical phase on such mechanisms applied to a sample of individuals. ${ }^{8}$ But exactly for the same reason, it is not easy to apply what has been learned in these laboratory-like settings to real life. This is known as the transfer problem. Games and other forms of simulation need to comply with certain requirements if they are to be effective. In this, De Geus (1988) and Senge (1990) seem to sustain opposite approaches. The former proposes that these models - or microworlds - do not need to be similar to real life but to actual mental models of the audience, because the goal is to induce change in their minds so that they can understand their world better. On the contrary, Senge (1990) proposes that microworlds need to fulfil the demands of: integration with the real world, a correct compression of time and space, isolation of variables, experimental orientation, pauses for reflection, theory-based strategy, and institutional memory to record the results. About the forms of simulation involving IT systems will be discussed later in the subsection devoted to them. More specialized testing such as that conducted in chemical laboratories or mechanical workshops are not addressed specifically in this paper, because each has its own scientific requirements of validity. Here we will only refer to Pisano's (1994) work because of the question of how close to actual implementation this kind of experiment should be. Comparing how biotechnology-based and chemical-based pharmaceutical firms work in their research for process development, he finds that laboratory testing (i.e., experimentation) is advisable in settings with a good general knowledge basis (in this case, chemical-based pharmaceuticals), while contexts with a poor knowledge basis (here, biotechnology-based companies) require closer to real-life experience testing.

Learning may unintentionally emerge from experience or it may be reinforced by means of some systematic processes (Huber, 1991). Among purposeful mechanisms, experiments and simulation have already been commented; another paradigmatic example is training. ${ }^{9}$ Thus, it seemed interesting to us to close this subsection talking with a discussion of training.

\section{Training}

To train means to teach somebody to do something by means of a practice or exercise. It seems to be commonly accepted that nobody can learn a practice without some kind of training ${ }^{10}$ but whether this training must be on-the-job or off-the-job, formal or informal, or previous to or during practice itself are contested issues. ${ }^{11}$ Given that our paper is about practical learning, we consider it advisable to refer to both formal and informal, on-the-job training.

As mentioned above, a good summary of the literature on training can be found in Salas and Cannon-Bowers' (2001) review in the Annual Review of Psychology. In this work, they examine literature on training needs analysis, antecedent training conditions, training methods and instructional strategies, and post-training conditions - in short, "the design, delivery, and evaluation of training in work organizations" (Salas and Cannon-Bowers, 2001, p. 473). One of their most relevant conclusions is that training cannot be isolated from the organizational

\footnotetext{
8 "Unlike subjects in decision experiments, managers must live with the consequences of their errors in judgment and faulty decisions" (Wood \& Bandura, 1989, p. 369).

${ }^{9}$ Killingsworth (1982) introduces a noteworthy distinction between (learning from) experience and training: given that "at least some learning is unavoidable whenever one works" (p. 265), in a hypothetical world of "pure" experience, training - costly as it is - would be avoidable, while learning would not.

${ }^{10}$ Contrary voices come from some extreme ideological positions, such as the avantgardes in arts occupations (Menger, 1999) or purely constructivist educational trends.

${ }^{11}$ For example, Lave and Wenger (1991) explicitly reject 'educational' or 'schooling' approaches to learning in practice.
} 
context and that failing to realise this is at the root of many failures of well-designed training plans. ${ }^{12}$ Another is the need for more research on on-the-job training. In addition the work shows eager interest in the possibilities of new communication and information technologies for training. Salas and Cannon-Bowers (2001) end by wishing a better collaboration between researchers and practitioners in the training field. Surprisingly enough, they do not provide any definition of training itself.

If Salas and Cannon-Bowers provide the academic panorama on training, Knoke and Kalleberg (1994) represent an example of analysis of the state of training practices in U.S. work organizations. The analysis includes factors such as organizations' size, unionization, demographic data regarding workforce, environment in terms of resource flow and information exchanges. They conclude that, overall, large firms with formalized structures and internal labour markets and in competitive, complex, resource-rich environments provide more training, and that unionization and workforce composition are not significant for training. ${ }^{13}$

Some studies on training are conducted from an economic stance, i.e., they calculate the benefits and costs of training. For example, Mincer (1962, p. 51) defines training as the "investment in acquisition of skill or in improvement of worker productivity." He provides demographic data regarding population as receptors of more or less investment in training. In particular, he points out women and African people as disfavoured groups, with underinvestment perpetuating a cycle of lower skills-unemployment. Killingsworth (1982) compares two human capital economic models, investment in training vs. learning-by-doing, aiming to merge both. In his model, he equates human capital to potential wage. Gattiker (1995) analyse public investment in training semi-skilled employees in order to ascertain whether investing in firm-specific training is more beneficial for all stakeholders - including government, taxpayers, companies and employees - than general skills training. After entering data such as post-training earnings and turnover, the answer is that investing in general skills training yields a higher return on investment, and that governments willing to improve neediest employees' opportunities should invest in vocational high schools and colleges.

In disagreement with a view based on mere rational economic calculation, other authors focus on training as a means for capabilities development, i.e., acquisition of expertise. It is the case of Bonner and Walker (1994), who study the effects of instruction and experience on the acquisition of procedural knowledge (i.e., knowledge related to performance or practice) by auditors. They describe experience as the combination of practice and feedback, but they are in fact describing a training process, because feedback is provided by someone controlling the learning process (a trainer). This person may simply describe the outcomes (outcomes feedback) or explain why the result is what it is (task-properties feedback). Only the latter leads to proper learning. Tan and Libby's (1997) work on the determinants of audit expertise concludes that "tacit managerial knowledge [...] could be improved by either formal classroom or on-the-job training" (p. 110, emphasis added), and that earlier training has effects on gaining tacit knowledge from later experience, i.e., training effects last long after the training phase itself. Maritan and Brush (2003) show significant differences of success in intra-firm best practices transfer depending on whether or not employees have received previous training. In fact, in the case studied by them, "[o]nly managers who were trained were able to understand how to

\footnotetext{
${ }^{12}$ Knoke and Kalleberg (1994) also argue that firms may adopt prevalent models in designing their training plans that do not match their actual needs.

${ }^{13}$ The latter expressly contradicts Mincer's (1962) earlier assertion that women and minorities receive less training.
} 
incorporate flow techniques into their areas" (Maritan and Brush, 2003, p. 952). In some units, additional training was required to fill these gaps, with the consequent delay. Epple et al.'s (1991) work reaches a similar conclusion regarding the benefits of training in intra-plant, intershift knowledge transfer. Burke (1995) shows another effect of training that is not strictly learning: apparently, there are differences between organizational levels and genders in how employees value training itself, i.e., if they consider it useful. In particular, higher levels and males deemed training more useful than the other groups. This is important because this judgment correlates with employees' perception of firm's support and commitment to quality, and, thus, their job satisfaction and intention to quit.

Finally, similarly to what happens with experiments, the fact that somebody has received training does not mean that he or she will apply what has been learned to real practice. This process is known as transfer of training. Salas and Cannon-Bowers (2001) enunciate a series of propositions and rules regarding transfer of training that highlight the influence of social and psychological climate (e.g., support from colleagues) and also time factors (delays in transfer produce skill decay). They also describe how scholars have designed different methods for measuring transfer.

\section{Learning and Imitation}

"Psychological theories traditionally have emphasized learning through the effects of one's actions. If knowledge and skills could be acquired only through direct experience, the process of human development would be greatly retarded, not to mention exceedingly tedious, costly, and hazardous." (Wood and Bandura, 1989, p. 362)

"In a social environment, learning from direct experience is supplemented by the diffusion of experience, that is, by copying others.” (Herriott et al., 1985, p. 299)

These quotes point to an essential trait of learning in practice, namely,imitation. ${ }^{14}$ There is imitation both in OL processes and in individual learning. Both could be simplified as 1) observing the other's (another organization's or another individual's) behaviour, 2) observing the outcomes of this behaviour, and 3) adopting it or avoiding it, depending on the observed outcomes. Obviously, this is not to say that personal experience is not important, but that both types of learning are complementary. On the other hand, although it has been also referred to as imitation - especially in the OL literature concerning learning from competitors or internal best practices transfer (Barney, 1991; Coff et al., 2006; Hedberg, 1981; Herriott et al., 1985; Huber, 1991; Lei et al., 1996; Levitt and March, 1988; Macdonald, 1995; March, 1991; Maritan and Brush, 2003) - it is important to not view this way of learning as mere mimicry (Barney, 1991; Foster and Rosenzweig, 1995; Herriott et al., 1985; Maritan and Brush, 2003; Senge, 1990). For example, according to Wood and Bandura (1989), mastery modelling is not simply copying; it is rather a complex process governed by attentional, representational, behavioural and motivational mechanisms.

\footnotetext{
${ }^{14}$ It is important to remember that we are talking about practical knowledge, which is the context of the quote. In theoretical knowledge, most of which is learned from external sources - teachers, publications, conferences -, there is the possibility of acquiring it without really imitating anybody. Although, even in this case, we could define imitation as following the same reasoning steps that the source has taken to reach the conclusion. In any case, it can be said that most of the knowledge we possess - either practical or theoretical - has originated from our contact with external sources, i.e., we basically learn from others.
} 
We will first examine modelling and related processes and then we will briefly describe vicarious learning. The difference between these two concepts is similar to that found in practice-based vs. experience-based learning approaches, i.e., the difference in theoretical bases. We will close this subsection with a discussion of socialization processes.

\section{(Role) Modelling and Related Issues}

We have seen how Wood and Bandura (1989) call this way of learning observational learning, or, simply, modelling. When applied to competence development, it is called mastery modelling. It is not rare to find the equivalent term role modelling (Cheetham and Chivers, 2001). Wood and Bandura (1989) base their proposal on social cognitive theory, which "explains psychosocial functioning in terms of triadic reciprocal causation" (pp. 361-362), in which "behavior, cognitive and other personal factors, and environmental events operate as interacting determinants" (p. 362). Hence, modelling occurs in a social environment. As explained above, they view modelling as a complex process that is not to be mistaken for mimicry. Another reason why this is so is that in many activities, others' rules and practices are learned in a sort of abstract form which enables them to be applied to multiple situations: there must be room for improvisation and innovation to suit particular circumstances. The process is facilitated if models verbalize their thought processes and action strategies. ${ }^{15}$

Two particular applications in practice of some sort of modelling are mentoring and simulations. The latter have been discussed above. They imitate real life - rules, procedures or roles, the functioning of machines, resistance of materials, and so on - in diverse ways with the purpose of learning. Here we will examine mentoring.

"For centuries wise men have offered counsel to the young. [...] Mentorship is the development process in many occupations: master-apprentice; physician-intern; and teacher-student" (Hunt and Michael, 1983, p. 475). Hunt and Michael, who provide an interesting overview of the characteristics of mentoring, portray it as a dyadic relationship placed at one extreme of a continuum of similar learning-oriented dyadic relationships, with peer pals at the other extreme. ${ }^{16}$ Citing diverse scholars, they characterize the mentor-protégé relationship as being "most intense or emotionally charged, hierarchical, parental, exclusionary, and elitist" (Hunt and Michael, 1983, p. 477) (See also Cheetham and Chivers, 2001, pp. 259-260). Hunt and Michael also describe mentor and protégé's traits and the stages of their relationship - initiation, protégé, breakup and lasting friendship. This relationship may be either formally or informally incepted (Armstrong et al., 2002; Cheetham and Chivers, 2001; Hunt and Michael, 1983), but apparently informal relationships are more fruitful (Armstrong et al., 2002; Cheetham and Chivers, 2001). Another additional characteristic is that the mentor is not only a counsellor, but also a role-model with a protective function (Armstrong et al., 2002; Barr et al., 1993; Hunt and Michael, 1983). The importance of making a good mentor-protégé match being obvious, there are some issues that

\footnotetext{
${ }^{15}$ Brown and Duguid (1991) describe narration - i.e., practitioners using "war stories" to transmit practical knowledge as one of the main features of work practice. (The other two are collaboration and social constructivism.)

${ }^{16}$ It is not difficult to locate coaching somewhere in the middle of this continuum. However, we have decided to tackle coaching at the end of this section because the common comparison of the coach with a scaffold (Cheetham and Chivers, 2001; Hunt and Michael, 1983) conveys the idea of a support tool which is removed when not needed. This allows us to include coaching along with other supports in the technological sphere (IT systems) and the knowledge sphere (instruction). Through mentoring, on the contrary, "skills and knowledge are passed on from successful mentors to organizations' future managers” (Hunt and Michael, 1983, p. 484, emphasis added). Learning relationships among peers will be addressed in socialization.
} 
influence this match. Armstrong et al. (2002), as noted before, point towards the harmonization of the respective cognitive styles, but there seems to be an equally relevant matter that is gender. First of all, there is evidence that male and female protégés make different use of mentoring, and, in addition, it seems that homophilic (i.e., same-gender) relationships are more fruitful than crossgender pairs, which involve a series of problems in both cases (Cheetham and Chivers, 2001; Hunt and Michael, 1983). ${ }^{17}$ Age differential is also included by Armstrong et al. (2002) among the influencing factors that have effects on the mentor's and protégé's perceived ideas generation, perceived similarity and mutual liking.

\section{Vicarious Learning}

The concept of vicarious learning is used mostly in OL literature, in particular in literature dealing with learning by experience. It means learning from others' (especially, other organizations') experience. For example, Foster and Rosenzweig (1995) describe how Indian peasants learn how to use high yielding seeds and new technologies both by doing and by neighbours' experience. Vicarious learning may be informally (Brown and Duguid, 2001; Macdonald, 1995) or formally (Cyert and March, 1963; Huber, 1991; Nonaka, 1994) sought, and focused on a narrow technological silo or open to different inputs (Huber, 1991).

Brown and Duguid (2001) show how the existence itself of cross-organizational communities of practice can facilitate vicarious learning - especially of the practice-embedded tacit knowledge - but, at the same time, it may originate unintended knowledge leaks. Hence, the importance of establishing some mechanism of boundary control (see also Coopey, 1995). If learning is seen as including imitation, and imitability is a condition for knowledge flows, it is important to avoid internal stickiness (i.e., no flow), but also external leakiness (Argote, 2005; Barney, 1991; Brown and Duguid, 1998, 2001; Coff et al., 2006; Lei et al., 1996; Sapsed et al., 2002).

On one hand, it is possible to learn from the spillovers coming from other organizations (Argote, 2005; Cohen and Levinthal, 1990; Foster and Rosenzweig, 1995) but, on the other hand, not all knowledge coming from external sources is equally good. It seems that that the chances are better if organizations and their situations are more similar (Baum and Dahlin, 2007) but there is also value in knowledge coming from sources external to the industry, because it may provide new and unexplored insights (Cohen and Levinthal, 1990).

Even if it is theoretically suitable, knowledge from external sources will not be useful "until it is internalized and applied to a firm's unique situation" (Simonin, 1997, p. 1158). This is the reason behind the elaboration that Cohen and Levinthal (1990) make about the organization's absorptive capacity. Firms must develop this capacity if they aim to exploit external knowledge (see also Soo et al., 2002). We do not see any reason why these concepts cannot also be applied to individual practical learning.

Levitt and March (1988) individuate diffusion of technologies as a way of acquiring external knowledge. The idea is that a lot of knowledge is embedded in technologies and may be extracted and copied by other organizations. However, this idea is challenged by Epple et al. (1991), who use a study of intra-plant (inter-shift) knowledge transfer to show that only part of the knowledge remains embedded in the technology and that investment in training is needed.

\footnotetext{
${ }^{17}$ This is interesting for practice, given that there are remarkably fewer female mentors available in certain "maledominated careers such as business, academia, and the professions" (Hunt and Michael, 1983, p. 477).
} 
On the other hand, adoption of new technologies itself poses some problems. Firstly, new technologies are not necessarily superior to old ones; experience shows that they first render fewer benefits and they start becoming profitable only after progressive adjustments (Young, 1993). Previous degree of expertise in practitioners is also determinant for the successful implementation of new technologies: experts succeed better (Foster and Rosenzweig, 1995), but too much human capital may be equally fatal for this implementation, because of the danger of stagnation (competency traps) (Jovanovic and Nyarko, 1996).

On the other hand, the possibility of vicarious learning requires paying attention to the individuals or groups of people belonging to the organization who have more external contacts (Brown and Duguid, 1991, 2001). These are usually known as gatekeepers (Cohen and Levinthal, 1990; Dodgson, 1993; Macdonald, 1995) or environmental scanners (Snell and Chak, 1998). In most cases, this task is performed in an informal way (Cohen and Levinthal (1990) call them receptors), but organizations may individuate and organize some groups who may play this role (Brown and Duguid, 1991). That means that there is space for a proactive search: that which looks for new opportunities. ${ }^{18}$ This is known as exploration.

Resources are scarce, and sometimes, organizations must choose between allocating them to doing what they already do well or to venturing into new territories. This is the famous exploration vs. exploitation dilemma (Baum and Dahlin, 2007; Brown and Duguid, 2001; Cohen and Levinthal, 1990; Cyert and March, 1963; Dodgson, 1993; Dyck et al., 2005; Hedberg, 1981; Levinthal and March, 1993; Macdonald, 1995; March, 1991; Nonaka, 1994; Nonaka et al., 2006; Spender, 2008; Weick and Roberts, 1993), which has its origin in Cyert and March's (1963) view of the organization as a system of competition for resources. "Learning from own experience tends to be exploitive" (Baum and Dahlin, 2007, p. 373). Exploration includes experimentation and vicarious learning. Diverse ways of overcoming this dilemma have been proposed. Brown and Duguid $(1991 ; 2001)$ advocate for a less hierarchical organization constituted as a community of negotiation, in which different groups negotiate and propagate a shared interpretation that leads to coherent practices. Pisano (1994) suggests that more exploration-focused or exploitationfocused activities may depend on the organization's general knowledge base. Young (1993) designs an economic model aiming to show mutual interdependence between learning-by-doing and invention: learning is needed for costly invention to become profitable, and it is seen as the exploration of the bounded profitability potential of recent inventions. In any case, organizations must seek a balance between both: excessive exploration may lead to chaos, excessive exploitation leads to paralysis (Levinthal and March, 1993). If this is a real dilemma in organizations, the individual's more limited resources make the choice between exploring new areas and exploiting present knowledge harder for him or her.

\section{Learning and Socialization}

Although Wood and Bandura (1989) are interested mainly in modelling mechanisms in the organization's key individuals, imitation mechanisms are constantly working across the organization in the form of socialization processes. These are the processes by which newcomers acquire the shared insights and learn the organization's practices (Argyris and Schön, 1978; Dodgson, 1993; Dyck et al., 2005; Levinthal and March, 1993; Levitt and March, 1988; March, 1991; Nonaka, 1994; Simon, 1991; Tsoukas, 1996). Socialization is, at one and

\footnotetext{
${ }^{18}$ In the literature, the discussion of "[w]hether focused search is largely reactive or proactive is related to the issue of determinism versus voluntarism in organizational change” (Huber, 1991, p. 99).
} 
the same time, integration in an organization, a mode of learning by imitation, and an identityshaping process. These processes are not to be understood as merely passive (Cook and Yanow, 1993): there is mutual interaction between individuals and organizational culture: newcomers may also modify prevailing beliefs and norms. Also Weick and Roberts (1993, p. 367) point to it when they note: "When experienced insiders answer the questions of inexperienced newcomers, the insiders themselves are often resocialized." Nonaka (Nonaka, 1994; Nonaka et al., 2006) envisions socialization from the individual point of view, as a stage of his knowledge conversion model, in which the transformation of tacit knowledge into explicit knowledge occurs in an individual-to-individual interaction. Dodgson (1993) shares a similar individualbased focus when he states that "routines are responses chosen by individuals" (p. 384), and then that individuals still choose whether to engage in them, or to resist socialization.

Socialization processes also have their bad side: Levinthal and March (1993) warn that excessive socialization produces an excessive homogeneity which finally impedes learning and innovation, because it institutes a closed-circle dynamic, facilitating the crystallization of errors. Nonaka (1994) says something similar when he explains the socialization process: pure socialization may lead to excessive specialization that makes knowledge impossible to transfer. Huber (1991, p. 105) adds another effect: "Socialization sometimes causes new members to unlearn. A consequence can be that the knowledge that the new members possessed upon entry becomes unavailable to the organization." This becomes paradoxical if the new member had been hired precisely because of this distinctive knowledge he or she possessed.

\section{Models of Professional Expertise}

Practitioners learn, and in learning they gradually develop themselves into competent or expert practitioners. In this subsection, the focus is the expert and how to become one through competence development.

\section{The Concept of Expertise}

In their work on the determinants of auditor expertise, Bonner and Lewis (1990) explain why experience and expertise are not the same. Experience is a sine qua non for the attainment of knowledge and, therefore, for becoming an expert, but it is not a sufficient measure for expertise:

"[I]f we define expertise as task-specific superior performance [...], there are also limitations to this approach. First, the evidence concerning the empirical relation between experience and performance is mixed. [...] Second, using experience to indicate expertise allows no conceptual basis for differentiating among auditors with the same level of experience, although it is likely, for example, that some audit managers may be more expert than others at specific audit tasks." (Bonner and Lewis, 1990, p. 2, emphasis added)

Note that here experience means having performed a certain number and kind of tasks within a certain period of time. Expertise is defined in terms of excellence or superior performance, and that is really what distinguishes the expert from the novice. Therefore, Bonner and Lewis (p. 6) propose an expertise model with the following components: "We believe [...] that experience combines with innate ability to develop knowledge, and that knowledge combines with ability to produce performance. Performance feedback further affects the development of knowledge." Good performers are put through further experiences and feedbacks and so they improve their expertise. In conclusion, it is not only the accumulation of experience (number of years in the practice) but also its quality in terms of knowledge and ability. Instruction and experience lead 
to knowledge in the three areas of general domain knowledge, subspeciality knowledge, and world knowledge. "Depending on the task, expert performance may require one or more of these types of knowledge and problem-solving ability" (Bonner and Lewis, 1990, p. 4). Libby and Tan (1994) use a similar knowledge-experience-ability interrelation. They also describe performance in one period affecting experience in a later period. Later on, Tan and Libby (1997) aim to expand Bonner and Lewis' model beyond technical knowledge, in any of its three forms, to include forms of tacit knowledge such as communication skills and interpersonal skills, because these become more and more important as one ascends the ladder of expertise (the others are already taken for granted).

Torbert (1994) describes transformational learning as the kind of learning typical of later-stage (i.e., expert) managers and which requires the development of what he calls triple-loop feedback, which is the capacity of seeing what action is suited for this particular developmental time and place. So for him, expertise can be detected through a peculiar judgment capability that is described as a kind of overview. King and Ranft (2001) state that the professional is the expert, and describe managerial expertise as a peculiar way of organizing environment so as to reduce searches and process new information. King and Ranft are talking from the research field on professional service firms (PSFs), which has developed an extensive production about expertise and professionalism (Boh et al., 2007; Chang and Birkett, 2004; Empson, 2007; Hitt et al., 2001; Løwendahl et al., 2001; Snook and Khurana, 2004; Teece, 2003). In these firms, the expert is considered to be the one possessing the know-how that is key for the organization, the dynamizer, the knowledge activist, the one at the core of the community of practice (Boh et al., 2007; Brown and Duguid, 1991; Cohen and Levinthal, 1990; Groysberg et al., 2008; Lave and Wenger, 1991; Nonaka, 1994; Nonaka et al., 2006; Rogers and Tierney, 2004; Teece, 2003), and this is also, no doubt, a power position (Alvesson, 1993; Coopey, 1995; Dodgson, 1993; Rogers and Tierney, 2004; Teece, 2003).

We have briefly seen diverse perspectives on the distinctive traits of the expert, but how does one become an expert? The path from novice to expert is not simple and requires a learning process. Some of the authors reviewed earlier describe expertise in terms of the possession of peculiar knowledge traits. But the knowledge they refer to is not theoretical but practical, because it refers to excellence in the performance of a particular practice, task, profession or occupation. We will now examine the scholars who view this practical knowledge in a broad sense, as the possession of certain qualities - knowledge and skills - that enable one to perform a task properly, and these qualities are competences. It is when competences are fully developed that we talk about expertise.

\section{Competence Development}

Sandberg and Pinnington (2009), in their work on professional competence, remark that there have been many different approaches to competences. All of them view learning as a process of competence development, but competences may be considered to be a prerequisite for a practice, an outcome (i.e., matching certain standards in performance) or a capability exercised during practice itself. Given that they - like us - are interested in the practical focus, they choose the third view. They also make an interesting distinction between those who follow an entity-based view of competences and those who adopt a relational perspective. The first see competences either as a body of applied theoretical knowledge or as particular physical or bodily characteristics. The second are more interested in work context and relational and practical aspects. This distinction is quite similar to that between epistemology of possession and epistemology of practice (Cook and Brown, 
1999; King and Ranft, 2001), which is applied to different conceptions of knowledge. Blackler (1995) points to it as well, with his alternative between knowledge as embodied, embedded, embrained, encultured, and encoded vs. knowing as a process (see also Lave and Wenger, 1991; Spender, 1996; Tsoukas, 1996; Wenger, 1998). All these authors adopt the practice-focused or relational approach, and reject the other as being static.

Sandberg and Pinnington (2009) explicitly place the knowledge, skills and attitudes models (KSAs) among entity-based approaches, but as a special case. The reason is, Sandberg and Pinnington note, that authors here ${ }^{19}$ expand the concept of "competences" beyond "knowledge" into "skills" and "attitudes", in a basically individual-focused perspective. In the introduction we showed how the use of a notion of practical knowledge embraces all three kinds of characteristics: knowing how to do something simultaneously includes having the applied theoretical knowledge required, adopting the right attitude towards action and having the skills required for the practice. Once acquired, competences remain in the possession of the practitioner in the form of procedural memory (Cohen and Bacdayan, 1994). On the other hand, competence is only proven in actual practice. As a consequence, we argue that the static and dynamic focuses need each other, and that there is no need for a dichotomy. ${ }^{20}$

Apart from this discussion, we may find many different proposals that could fit into the category of developmental models, because they point out some important competences that must be developed along the path to expertise. For example, Brown and Duguid (1998) advocate the development of dialectical thinking in order to be able to grasp the current complexity. Similarly, Senge (1990) views excellence as the mastering of five disciplines - systems thinking, personal mastery, mental models, building shared visions, and team learning, and ends by suggesting a sixth, holistic thinking. Inkpen and Crossan (1995) mention integrating learning as an important requirement for managers in collaborative learning processes.

Other authors focus on the acquisition of competences that are specifically required for learning (i.e., learning to learn): collaborative know-how (Inkpen and Crossan, 1995; Simonin, 1997), absorptive capacity (Cohen and Levinthal, 1990; Inkpen and Crossan, 1995), the ability of double-loop learning or higher-level learning (Argyris, 1976; Argyris and Schön, 1978; Fiol and Lyles, 1985; Torbert, 1994).

Lastly, we could mention another group of scholars who centre on the prior requirements for competence development (i.e., requirements for learning). We have mentioned them in the section on the antecedents of learning: the importance of assessing learners' learning styles (Kolb and Kolb, 2005; Sims, 1983), motivational aspects such as self-efficacy and goal systems (Cyert and March, 1963; Wood and Bandura, 1989), empowerment (Conger and Kanungo, 1988; Snell and Chak, 1998), the degree of stress suffered by learners (Cangelosi and Dill, 1965), and so on.

As can be seen from the authors cited, competence development models have been applied to organizations. Indeed, a number of authors working in the OL field are interested in the development of organizational core competences (Argyris and Schön, 1978; Fiol and Lyles, 1985; Lei et al., 1996; March, 1991; Stein and Zwass, 1995; Wood and Bandura, 1989).

\footnotetext{
${ }^{19}$ Salas and Cannon-Bowers (2001) represent an example of the use of the KSAs model by applying it to the different aspects of training. They envision training as a KSAs development mechanism. See also Stevens and Campion (1994).

${ }^{20}$ We have already seen how Bonner and Lewis (1990) and Libby and Tan (1994; Tan and Libby, 1997) describe competences in terms of knowledge and abilities.
} 
But the idea itself of learning as a competence development process is not without problems. Torbert (1994), for example, states that there is no recipe for transformational managerial learning (the learning which turns managers into later-stage managers and, thus, transforms organizations), that there is an "aura of masculine elitism that initially seems to emanate from developmental theory" (Torbert, 1994, p. 67), but that "[t]o be a member of a small elite, however, or to suggest that the leadership actions of members of such a small elite may have special significance, is not to be elitist" ( ibid.). A developmental leader by definition is not elitist. In other words, achieving a level of expertise may lead to a power position and a misuse of this power (Alvesson, 1993; Coopey, 1995), but the real leader does not fall prey to this temptation. On the other hand, becoming competent is not always the same as achieving success in the long run. There are competence traps, which occur when competent practitioners become accommodated to success, now that it is certain, and avoid any innovative (i.e., having an uncertain outcome) activity. We will talk about these and other pitfalls to learning in the final section.

In the following sections, we will discuss some additional tools commonly used to support learning.

\section{The Role of Instruction, Coaching and Information Technologies}

It is clear from all that has been said until now that practical learning can either be acquired as a necessary but serendipitous by-product of interaction - be it social, with the market or with products and technologies - (Young, 1993) or it can be sought or enhanced via diverse learning mechanisms - such as expert teams, knowledge-sharing meetings, training and development plans, RandD departments, gatekeepers, knowledge activists, and so on. In the second case, and to make these mechanisms work, organizations, and especially companies, have made extensive use of certain support tools. There are three support tools we have considered to be particularly worth highlighting: instruction - understood as some kind of formal transmission of explicit knowledge -, coaching, and new information and communication technologies.

\section{Practical Learning and Instruction}

Given that learning in and $a$ practice is mainly related with action, we may ask the question: does instruction really matter for practical learning? If by instruction we understand the mere teaching of theoretical knowledge, it seems that it will contribute little to practice. Cheetham and Chivers (2001) define instruction as: "the inculcation of specific knowledge or skill-related principles to one or more individuals at the same time". That means that instruction may be understood in a broad sense that ranges between applied scientific knowledge (i.e., conceptual knowledge related to the practice) and explicit some rules of thumb (e.g., instructions for using a machine or standard procedures). However, it is explicit knowledge what is mainly inculcated.

Likewise, Raelin (1997) makes a clear distinction between work-based learning and instruction, understood here as theoretical work-related knowledge. In line with how practical learning has been described in our paper, Raelin states that work-based learning does not consist of the traditional "adding a layer of experience onto conceptual knowledge" (p. 564). But he does make room for instruction: theory "may be acquired in concert with practice. Theory may also be introduced after rather than before experience in order to question the assumptions of practice. [...] Theory makes sense only through practice, but practice makes sense only through reflection as enhanced by theory" (p. 564, emphasis in original). This balanced proposal is noteworthy because, as stated before, some scholars - typically from pragmatist and constructivist stances - reject any relationship between theory and practice or even any kind of 
formal instruction for learning a practice (Cook and Yanow, 1993; Lave and Wenger, 1991; Spender, 1996; Tsoukas, 1996).

Bonner and Walker's (1994) work addresses the effects of instruction and experience or practice in the acquisition of audit expertise - here, procedural knowledge. Procedural knowledge - of rules or steps for performing a practice of the type if $A \rightarrow B$, acquired in practice - and declarative knowledge - of facts and definitions, acquired in formal education -are the two different types of explicit knowledge we may find regarding practice. And, as has been said above, what is taught and learned in instruction is explicit knowledge. Bonner and Walker admit instruction both before and after performance and give it different names: instruction and feedback, respectively. In their model, "experience" is equal to practice or doing, "instruction" can be either providing "how-to rules" (lists of steps or procedures) or "understanding rules" (explanations about the steps), and feedback can be "outcome feedback" (information about the outcome) or "explanatory feedback" (about why the outcome occurred). They conclude that: 1) experience is necessary even for the acquisition of explicit practical knowledge, 2) experience alone is not sufficient, 3) understanding rules are more effective than how-to rules, but 4) feedback is always necessary, and 5) only explanatory feedback is sufficient for learning when combined with experience. Finally, 6) a general problem-solving ability is also positively related to procedural knowledge acquisition. All this refers to the learning of explicit practical knowledge but nothing is said about the acquisition of tacit practical knowledge. What about the effects of instruction on tacit knowledge?

Precisely, Tan and Libby (1997, p. 110) conclude their paper by suggesting that "[a]lthough tacit managerial knowledge is by definition knowledge that is normally not directly taught in school, it could be improved by either formal classroom or on-the-job training." Something similar was already present in Mincer's (1962) early paper on training: he envisioned formal school instruction as not sufficient, and graduation as "the end of a more general and preparatory stage, and the beginning of a more specialized and often prolonged process of acquisition of occupational skill” (p. 50). Also King and Ranft (2001) consider the need to acquire a basis of general knowledge - upon which to specialize - that managers receive either in MBAs or with years of experience, ${ }^{21}$ and members of PSFs acquire through their respective university degrees.

\section{Coaching}

In their review, Cheetham and Chivers (2001) define coaching as a "one-to-one learning support tailored to the needs of an individual". We have already mentioned the difference between coaching and mentoring. In fact, Armstrong et al. (2002) consider coaching to be part of the mentor's functions in the career aspect, which, combined with psychosocial functions, comprise the dual aspect of the mentor's role. In short, a mentor can be a coach, but the coach's specific function is to support career development; work issues are his or her subject. The mentor is always a senior colleague; the coach is not necessarily so, he or she can be a peer or an external consultant, and the relationship is usually mediated by a contract. Mentorship relationships are typical of the early stages of a career, while coaching is more proper to midcareer (Feldman and Lankau, 2005). We have also seen that the coach has been compared to a scaffolding (Cheetham and Chivers, 2001; Hunt and Michael, 1983). "Like real scaffolding, the support can be adjusted as necessary, according to the learner's needs. It can also be dismantled when it is no longer

\footnotetext{
${ }^{21}$ Note that with this, King and Ranft also imply that an MBA or other formal instruction process may considerably shorten the learning period.
} 
required" (Cheetham and Chivers, 2001, p. 257). According to Cheetham and Chivers, some scholars view providing feedback and directing the trainee's attention to essential factors as the main functions of the coach, who also adjusts the learning process as it evolves.

Given the proliferation of professional coaches, there is some controversy concerning who should claim to be a coach and if a certification is needed. According to Feldman and Lankau (2005), for some authors, only psychologists are qualified to be coaches, because they can detect the root of some behavioural and social problems and correct them instead of simply helping the learner to modify his or her behaviour at work (Berglas, 2002), while for others, it is essential that coaches know the business context. To date, the field remains generally unregulated, and academic research on coaching is largely undeveloped (Feldman and Lankau, 2005).

Hunt and Michael (1983) also place coaching within the functions of the mentor, and state that successful managers often demonstrate their leadership by adopting coaching functions. Hackman and Wageman (1995) believe that coaching is a sine qua non for learning in organizations, and that managers must provide this support for their employees, including those at the front line. This idea is common in the literature on the learning organization.

\section{IT Systems and New Communication Technologies}

There is no doubt that new information and communication technologies have revolutionized organizations. The progress in computing and data processing unleashed a wave of excessive enthusiasm about these technologies' possibilities in organizations in the late 1970s and 1980s (Dreyfus, 1992; Nonaka et al., 2006; Stein and Zwass, 1995). This trend had its roots in an excessively mechanistic conception of human individual and social behaviour. For example, Cohen and Bacdayan (1994) make an interesting critique of the application of information systems to design and redesign routines: human routines include a high factor of contingency and are resistant to codification. ${ }^{22}$ Beamish and Armistead (2001, p. 108) distinguish between "data ('points of reality'), information ('organized data') and knowledge ('information, context and experience')", i.e., information to which meaning has been added (see also Gallupe, 2001; Huber, 1991). ${ }^{23}$ This distinction makes it clear that information systems are facilitators but do not substitute for learning and knowledge management processes.

Stein and Zwass (1995), when talking about organizational memory systems, describe some of these tools' limitations, which are not due to the systems' lack of development but to their own nature and their interaction with a human environment. Similarly, Alavi and Leidner remark that there are challenges coming from different fronts: first, there is the problem of size and quantity of information, which is not always directly correlated with learning; secondly, there are problems of re-use, updating and trust regarding the use of these technologies; usability and system quality are also problematic; finally, not all kinds of knowledge are equally codifiable. ${ }^{24}$ Face-to-face, and even physical, interactions are necessary for acquiring tacit knowledge (Coff et al., 2006; Cook and Yanow, 1993; Davenport et al., 1998; Hansen et al.,

\footnotetext{
${ }^{22}$ See also the more fundamental and famous critique of Dreyfus (1992), which is not addressed - as some believe to IT in general, but to certain AI projects and the assumptions supporting them.

${ }^{23}$ Soo et al. (2002, p. 131) adopt a different perspective: "[t]rue knowledge, by definition, is non-codified. As soon as it becomes codified and transmittable it ceases to be knowledge and it becomes data." Something similar is sustained by Alavi and Leidner (2001, p. 109): "Knowledge becomes information once it is articulated and presented in the form of text, graphics, words, or other symbolic forms."

24 "Practices always have performative aspects that go beyond what is codified in organizations" (Miller, 2008, p. 945).
} 
1999; Hitt et al., 2001; Lave and Wenger, 1991). The reason for this is two-fold: tacit is, by definition, very difficult to codify, and it is difficult to design IT systems capable of dealing with tacit knowledge without resorting to some kind of codification. ${ }^{25}$ We will see that the social interaction needed to transmit this knowledge cannot be substituted perfectly by virtual channels. In addition, there are occupations that include a great deal of bodily skills in their practice, and these skills can only be acquired through physical interaction with physical objects (e.g., working tools, bodies, manufactured products).

Given their properties of compressing space and time, once taken as tools and not as the "organ" of learning, the possibilities opened by these technologies are immense. In fact, the widespread use of information systems is included by Pedler et al. (1989) as one of the main traits of the learning organization, but, as with any other kind of tool, this use must be matched to the organization's needs (Brown and Duguid, 1998). For instance, Hansen et al. (1999) suggest that companies offering more personalized services need IT systems that help them internal communication and in finding people who possess the required knowledge; on the contrary, more standardized firms follow a codification model and, thus, need systems more similar to archives or libraries, with search engines to find the wanted document. ${ }^{26}$ Brown and Duguid (1998) remark that, though fluidity and absence of formalities seem the ideal, in some organizations, such as high-security demanding organizations, fragmentation of knowledge and strict filtering of who accesses what information are a must.

Generally speaking, new technologies are used for three types of learning: dealing with data i.e., data searching, selection, storage, retrieval, updating and so on -, computer-based simulations, and communication - supporting internal networks, virtual teams and the like.

Regarding data processing, in order for organizations to learn, they must manage their knowledge resources properly. There is a large field of literature on knowledge management systems (KMSs) and organizational memory systems (OMSs) that include - and sometimes study exclusively (Alavi and Leidner, 2001) ${ }^{27}$ - the role of IT in these processes. Gallupe (2001, p. 61) defines KMSs as a "means to aid organizations in creating, sharing and using knowledge." Among these means, there is IT. ${ }^{28}$

Within the different practices constituting KM - recognition of problems, problem solving, memory or storage, and dissemination -, Gallupe (2001) envisions IT as especially helpful for knowledge storage purposes. This is not a surprise, given that data storage, one of the first functions historically performed by computers, is the constitutive aspect of memory. Huber (1991) concurs with this idea: information technologies can expand the possibilities of human memory, which is poor in itself, far beyond its limits, and also overcome other problems such as turnover. Huber also notes that the main problem is the storage of soft information, which resides in experts. Moreover, there are issues such as data interpretation and cultural, structural

\footnotetext{
${ }^{25}$ Coff et al. (2006) propose a model of knowledge transfer without having to codify knowledge, via patternrecognition and information-tracking systems, and the use of telecommunications.

${ }^{26}$ These differences are reminiscent of the description that Hazlett et al. (2005) give of two different approaches to the use of information systems, computational - which is techno-centric, and focuses on information codification, storage and transfer - and organic - which is people-centric, and uses IT to facilitate personal interactions.

${ }^{27}$ They do state that KM does not reduce to IT, but, on the other hand, it is difficult to make this match with the idea that KMSs - which are the tools used to manage knowledge - are the same as information systems.

${ }^{28}$ Soo et al. (2002) conclude that KM cannot be explained through IT, which is insufficient, but through innovation and intangible asset management.
} 
and behavioural aspects that belong to the human component of KM. This is why Stein and Zwass (1995) argue that information systems, even for managing organizational memory, must be conceived in combination with human expertise; the other position - pretending that electronic devices will do all the work - is unrealistic. Alavi and Leidner (2001) expand their work to all the other $\mathrm{KM}$ practices ${ }^{29}$, providing an account of the diverse services that information systems can render to organizations.

New technologies are also used for simulation. The more similar training conditions are to actual practice, the more accurate the learning is. However, in some settings, real practice may be problematic, for example, it may be dangerous or costly. So designs are tested and practices rehearsed with the help of electronic equipment. Salas and Cannon-Bowers (2001) explain that simulations' fidelity to detail is not as important as that their ability to capture the KSAs to be learned. Research suggests that more schematic simulations may facilitate the transfer of complex skills. Salas and Cannon-Bowers state that very often simulation is applied with little regard for what research about learning and training says. They also refer to the use of computers for games as a training tool.

Finally, the use of information systems to facilitate communication and networking is well known. Among other possibilities, learners can connect with distant practitioners who have the knowledge required, teams can meet virtually, and forums for best practice sharing can be designed. It seems that these functions are most appropriate for the transfer of tacit knowledge (Coff et al., 2006). However, the consequences of the introduction of these technologies are ambivalent: they do save time and money and make knowledge available to more people but, on the other hand, members of the organizations have to work under more pressure, which may result in taking harsh decisions, and abuse of virtual contacts may result in a gradual impoverishment of the much needed social capital (Nahapiet and Ghoshal, 1998). Thus, what seems to facilitate learning and development at the same time seems to hinder it (Prats and Agulles, 2011). Brown and Duguid (1998) caution that the dissemination of information networks does not necessarily result in the dissemination of knowledge networks, which require a social context: reciprocity must be guaranteed for this to happen. Interestingly, they highlight how "explicit design strategies for exchanging information are repeatedly subverted by users who press for a social network" (Brown and Duguid, 1998, p. 107). As mentioned before, this social interaction is so much needed for learning some practices that no virtual instrument can replace it. Once again, for tacit knowledge sharing, a considerable degree of face-to-face interaction is necessary.

\section{Obstacles to Learning in Practice}

"Learning does not always lead to veridical knowledge. [...] Entities can incorrectly learn, and they can correctly learn that which is incorrect." (Huber, 1991, p. 89, emphasis added)

There are a series of circumstances and individual and organizational behaviors that act as learning inhibitors or are the cause of certain learning disabilities. The result is that the process of learning itself may become flawed or what has been learned either is not really useful for the organization or is even counterproductive. We will explore all these mechanisms, whose destructive power is increased precisely because they are unnoticed. In the case of organizations

\footnotetext{
${ }^{29}$ Their list is somewhat different from Gallupe's (2001): knowledge creation, storage and retrieval, transfer and application.
} 
and the individuals inside them, we may find that some conditions for learning are missing. In addition, there are other difficulties inherent to the learning process itself. These are the items that we will comment on in this section.

\section{Shortcomings in Learning Conditions}

The lack of proper conditions determines an impoverishment or even absence of learning by both individuals and the organization. Without seeking to be exhaustive, we will follow the same outline used to explain these conditions to show how learning can be impeded.

\section{Missing Characteristics in the Learner and Motivational Issues}

The first impediment to be examined is the lack of cognitive and other abilities conducive to learning. For example, lack of heed (Weick and Roberts, 1993), attention (Eisenstein and Hutchinson, 2006), absorptive capacity (Cohen and Levinthal, 1990) or receptivity to corrective feedback (Argyris, 1976), or a crystallized single-loop learning style (Argyris and Schön, 1978; Dodgson, 1993), are clear inhibitors for initiating a learning process. For example, Maritan and Brush (2003) report a flawed best-practices transfer process due to differences in management's willingness to implement the process and their respective ability in terms of absorptive capacity. Social competences have also been highlighted as important learning facilitators (Edmondson et al., 2001; King and Ranft, 2001; Simonin, 1997): many problems in learning processes come from troubled social relationships (Maritan and Brush, 2003; Nahapiet and Ghoshal, 1998).

There are also issues related to goals and expectations. The goal of learning processes is success, but we have seen that definition of success is ambiguous: success indicators may change over time, and the definition of success also depends on who judges the process and what criteria are applied (Alvesson, 1993; Carroll, 1998; Levitt and March, 1988). Brown and Duguid (2001) refer to conflicting criteria among communities of practice coexisting inside the same organization (see also Carroll, 1998). On the other hand, investment in exploration depends on the level of aspiration, and that leads to the organization entering either a learning circle if this level is high or a vicious circle if it is low (Cohen and Levinthal, 1990; see also Baum and Dahlin, 2007). ${ }^{30}$

The lack of self-efficacy - or, as Conger and Kanungo (1988) put it, feeling powerless -, or its excess may lead to bad appreciations of outcomes and, therefore, to changes in expectations and behaviour (Levinthal and March, 1993). There are motivational aspects related to selfefficacy and empowerment (e.g., senior management or organizational support to learning) that, if they are missing, may decrease learners' efforts. Barriers to the sharing of information which, as we will see shortly, are typical of hierarchical organizations - directly affect learning.

\section{Environmental characteristics}

Adaptive models of learning have highlighted the enormous influence of the environment in learning processes. We will review external environmental and internal organizational conditions for obstacles to learning.

If we start with external environmental conditions, there is the issue of environmental turbulence. Turbulent environments - i.e., rapidly changing and with a high level of uncertainty

\footnotetext{
${ }^{30}$ Note that low level of expectations may be due to previous failure - 'we'd better not waste effort' - or to previous success - 'If ain't broke, don’t fix it'. These are success and failure traps that will be tackled later.
} 
- have already been mentioned, as well as the fact that a moderate level of turbulence triggers learning. Too much turmoil inhibits the possibility of orienting or mapping because it overloads the system (Hedberg, 1981; Levinthal and March, 1993). There is a strong temptation to change course randomly and repeatedly in an attempt to find a new route (Macdonald, 1995). Under such conditions, it will take some time to start learning from this new experience. Moreover, the uncertainty this situation produces is the cause of discomfort stress (Cangelosi and Dill, 1965), which, in excess, may paralyze potential learners.

On the other hand, in an excessively peaceful environment, where outcomes are highly predictable, the organization becomes trapped in its own success (the "competence trap"), and starts exploiting already possessed knowledge to the detriment of innovation. It becomes increasingly dependent on well-trodden paths, it loses flexibility and mutual learning among the organization's members degenerates. Finally, the organization finds itself unable to respond to changes in the panorama (Cohen and Levinthal, 1990; Hedberg, 1981; Inkpen and Crossan, 1995; Lei et al., 1996; March, 1991).

The general knowledge base and technological development along with socio-political stability have already been cited as learning enhancers (Brown and Duguid, 1998; Foster and Rosenzweig, 1995; Herriott et al., 1985; Lave and Wenger, 1991; Levinthal and March, 1993; Miller, 2008; Pisano, 1994; Soo et al., 2002). If these conditions are poor, it is difficult to provide the means for organizations and individuals to learn.

The internal organizational environment may also cause difficulties to potential learners. Roughly following Pedler et al. (1989), we may find challenges in the availability of learning resources, in the organization's culture, structure or practices, and in the use of information systems. Regarding the access to learning resources, Lave and Wenger (1991) exemplify a setting in which newcomers denied access to legitimate peripheral participation are prevented from learning. Similarly, Maritan and Brush (2003) report that failing to train organization members in an important affected area during the implementation of a new process leads to failures in best practices transfer. Mincer (1962) had shown the low investment in training-low skills-underemployment cycle in marginal population groups, and this can be also be detected in some organizations.

Cultural, structural and political issues are very commonly cited in OL literature as crucial for favouring or hindering learning, and the list is quite extensive. There are problems such as competition for power or power abuse and lack of empowerment (Akbar, 2003; Alvesson, 1993; Argyris, 1976; Blackler, 1995; Coff et al., 2006; Conger and Kanungo, 1988; Coopey, 1995; Davenport et al., 1998; Morris and Moore, 2000; Penrose, 1959; Snell and Chak, 1998; Torbert, 1994; Wenger, 1998); there are organizations that lack psychological safety, and thus, prevent learning from mistakes (Cannon and Edmondson, 2005; Edmondson et al., 2001; Lee et al., 2004; Morris and Moore, 2000; Tucker and Edmondson, 2003); there are rigid, bureaucratic, hierarchical organizations in which an excess of control leads to feelings of fear and mistrust and double-faced behaviours (Argyris, 2003; Hedberg, 1981; Morris and Moore, 2000); at the other extreme, there are organizations in which generalized anarchy has led to destructive chaos (Nonaka, 1994); in some organizations, there are tensions between individuals and subgroups and also between diverse belief systems (Cangelosi and Dill, 1965; Hedberg, 1981; Inkpen and Crossan, 1995); we may also find different forms of political manoeuvring that lead to information distortion: the information transmitted is incomplete, biased, censored, and so on (Argyris, 1976; Argyris and Schön, 1978); finally, there are organizations in which 
knowledge flows so freely and becomes so imitable that it easily leaks to competitors (Brown and Duguid, 2001; Coff et al., 2006).

The misuse of IT systems and the problems they may introduce into learning processes have already been discussed extensively earlier on.

\section{Difficulties Inherent to the Learning Process}

March,Levitt and Levinthal (Levinthal and March, 1993; Levitt and March, 1988) devote especial attention to some pitfalls that learning processes - or at least some of them - pose to learning itself. The first group of these challenges belongs to the notion of experience itself. The second is an effect of the simplification and specialization that usually accompanies learning processes.

\section{Regarding Experience}

Learning from experience is not a simple process, and it involves some characteristics that may become traps. They are cleverly summarized by Levitt and March (1988), but there are many other scholars pointing at the same problems.

First of all, there are sample problems: how many cases are enough to generalize from? What if the event happened only once? (March et al., 1991) Is it correct to infer the future from the the past? Senge (1990) talks about the delusion of learning from experience, highlighting the many times that the reason for taking a risk has been "nothing bad has happened until now" (see also Macdonald, 1995). ${ }^{31}$ This leads us to the next issue, that is, the use of history (or past experiences) for learning. Experience and history are subject to interpretation, and interpretation depends on the framework that is applied (Brown and Duguid, 1991; Daft and Weick, 1984; Huber, 1991; Inkpen and Crossan, 1995; Marshall, 2008; Nicolini and Meznar, 1995; Spender, 1996; Tsoukas, 1996). Which interpretive framework is used is vulnerable to politics (Levitt and March, 1988; Macdonald, 1995; Stein and Zwass, 1995). This is the reason why the much-acclaimed myths revision is not always right: dominant beliefs may be imposed over real environmental responses (Hedberg, 1981). Cangelosi and Dill (1965) note how eager to reform some new managers are.

In addition, there is always the danger of superstitious learning, i.e., a wrong cause-and-effect coupling, that leads to insist on certain actions that are, at best, unproductive, under the belief that, sooner or later, they will produce the expected outcome (Fiol and Lyles, 1985; Hedberg, 1981; Huber, 1991; March et al., 1991; Morris and Moore, 2000; Shrivastava, 1983; Simonin, 1997).

Learning from experience also requires a good use of memory. In addition to the problems offered by individual human memory, there are others that are typical of the organizational memory systems used by members precisely to learn: recording may be incomplete; relevant information may be ignored while irrelevant information is kept; tacit and explicit knowledge require different handling; and there may be inconsistencies in recording. Conservation or maintenance of knowledge is also problematic - for example, Cangelosi and Dill (1965, p. 199) talk about discontinuities produced by top management turnover -, it may be difficult to retrieve recorded knowledge; and, finally, the information retrieved and applied may not be the most suitable for solving the problem (Levitt and March, 1988; Stein and Zwass, 1995).

\footnotetext{
${ }^{31}$ Cyert and March (1963) state that current aspiration is an optimistic extrapolation of past achievement and past aspiration.
} 
To conclude, there is the danger we have already mentioned of mere mimicry when the experience from which one is learning is second-hand (i.e., learning from other people's experience). The applicability of models must be assessed.

\section{Effects of Simplification and Specialization}

According to Levinthal and March (1993), learning always requires a dual process of simplification and specialization. This is associated with a congenital myopia that raises a threefold danger of overlooking the long run, overlooking the large picture, and overlooking failure.

The first myopia consists of ignoring the long run. One of the first consequences are the competence or success traps (Cohen and Levinthal, 1990; Inkpen and Crossan, 1995; Jovanovic and Nyarko, 1996; Lei et al., 1996; Levinthal and March, 1993; Macdonald, 1995): those who develop certain competences in certain practices to the detriment of others become more and more path-dependent, they fall into self-reinforcing behaviour, stagnation and inability to face rapid changes. The counterpart are the failure traps (Levinthal and March, 1993), that also lead to paralysis through feelings of powerlessness. There are other effects of this myopia, such as erosion of enactment (reality makes over-simplistic models unsustainable), power traps (organizations that are powerful enough to transform their environment are not always able to react to novelty), and problems related to excessively detailed knowledge inventories.

The second myopia consists of ignoring the whole for the part. This has a number of symptoms. One of them is what Hedberg (1981) calls "audience learning”, that is, a weak coupling between individuals' and the organization's actions. As a result, part of the system is learning apart from the rest, and, in turn, the rest piggybacks onto those making the effort. This process leads to a gradual, generalised underinvestment in exploration or creativity (Levinthal and March, 1993). Other consequences have been individuated by Brown and Duguid (1998) as the dark side of communities of practice: rigidity, knowledge stickiness, blindness and self-deluding attitudes, that make it necessary to properly manage relationships among communities. Also Dodgson (1993) and Huber (1991) denounce parochial and self-defensive attitudes that lie at the root of the famous not-invented-here syndrome $(\mathrm{NIH})$, an illness that consists of refusing to consider any contribution coming from sources external to one's own group (Cohen and Levinthal, 1990; Dodgson, 1993; Macdonald, 1995; Simon, 1991). Morris and Moore (2000), Senge (1990) and Argyris and Schön (1978) envision ignoring the larger picture as a frequent feature of control or hierarchical regimes in organizations.

The third and last myopia leads to ignore failures. It may appear, as stated above, when selfefficacy produced by previous success becomes over-confidence, but it also may appear in human groups with policies or organizations that penalize failure, its disclosure or its amendment (e.g., for lack of psychological safety or lack of time to investigate root causes) (Baum and Dahlin, 2007; Cannon and Edmondson, 2005; Edmondson et al., 2001; Morris and Moore, 2000; Tucker and Edmondson, 2003). This kind of behaviour is what Argyris and Schön (1978) call "skilled incompetence" and "skilled unawareness". Fear of failure also produces a kind of stress called performance stress (Cangelosi and Dill, 1965), and that may also be harmful.

If we examine the descriptions of all the pitfalls to learning, we can see that they share a combination of organizational and environmental factors and erroneous individual behaviours such as power abuse, information hiding, errors in appraisal of the past, and so on. 


\section{References}

Akbar, H. (2003), Knowledge Levels and their Transformation: Towards the Integration of Knowledge Creation and Individual Learning*, Journal of Management Studies 40 (8): pp. 1997-2021.

Alavi, M. and D. E. Leidner (2001), Review: Knowledge Management and Knowledge Management Systems: Conceptual Foundations and Research Issues, MIS Quarterly 25 (1): pp. 107-136.

Alvesson, M. (1993), Organizations as Rhetoric: Knowledge-Intensive Firms and The Struggle with Ambiguity, Journal of Management Studies 30(6): pp. 997-1015.

Argote, L. (2005), Reflections on Two Views of Managing Learning and Knowledge in Organizations, Journal of Management Inquiry 14 (1): pp. 43-48.

Argote, L. and H. R. Greve (2007), A Behavioral Theory of the Firm 40 Years and Counting: Introduction and Impact, Organization Science 18 (3): pp. 337-349.

Argyris, C. (1976), Single-Loop and Double-Loop Models in Research on Decision Making, Administrative Science Quarterly 21 (3): pp. 363-375.

Argyris, C. (2003), A Life Full of Learning, Organization Studies 24 (7): pp. 1178-1192.

Argyris, C. and D. A. Schön (1978), Organizational Learning: A Theory of Action Perspective, Addison-Wesley: Reading, MA.

Armstrong, S. J., C. W. Allinson and J. Hayes (2002), Formal Mentoring Systems: An Examination of the Effects of Mentor/Protégé Cognitive Styles on the Mentoring Process, Journal of Management Studies 39 (8): pp. 1111-1137.

Arrow, K. J. (1962), The Economic Implications of Learning by Doing, The Review of Economic Studies 29 (3): pp. 155-173.

Barney, J. (1991), Firm Resources and Sustained Competitive Advantage, Journal of Management 17 (1): p. 99.

Barr, L. L., K. Shaffer, K. L. Valley and B. J. Hillman (1993), Mentoring. Applications for the Practice of Radiology, Investigative Radiology 28 (January): pp. 71-75.

Baum, J. A. C. and K. B. Dahlin (2007), Aspiration Performance and Railroads' Patterns of Learning from Train Wrecks and Crashes, Organization Science 18 (3): pp. 368-385.

Baumard, P. (2002), Tacit Knowledge in Professional Firms: the Teachings of Firms in Very Puzzling Situations, Journal of Knowledge Management 6 (2): pp. 135-151.

Beamish, N. G. and C. G. Armistead (2001), Selected debate from the arena of knowledge management: new endorsements for established organizational practices, International Journal of Management Reviews 3 (2): p, 101.

Berglas, S. (2002), The Very Real Dangers of Executive Coaching, Harvard Business Review 80 (6): pp. 86-93.

Blackler, F. (1995), Knowledge, Knowledge Work and Organizations: An Overview and Interpretation, Organization Studies 16 (6): pp. 1021-1046. 
Boh, W. F., Y. Ren, S. Kiesler and R. Bussjaeger (2007), Expertise and Collaboration in the Geographically Dispersed Organization, Vol. 18: pp. 595-612.

Bonner, S. E. and B. L. Lewis (1990), Determinants of Auditor Expertise, Journal of Accounting Research 28 (3, Supplement): pp. 1-20.

Bonner, S. E. and P. L. Walker (1994), The Effects of Instruction and Experience on the Acquisition of Auditing Knowledge, The Accounting Review 69 (1): pp. 157-178.

Brown, J. S. and P. Duguid (1991), Organizational Learning and Communities-of-Practice: Toward a Unified View of Working, Learning, and Innovation, Organization Science 2 (1, Special Issue: Organizational Learning: Papers in Honor of (and by) James G. March): pp. 40-57.

Brown, J. S. and P. Duguid (1998), Organizing Knowledge, California Management Review 40 (3): pp. 90-111.

Brown, J. S. and P. Duguid (2001), Knowledge and Organization: A Social-Practice Perspective, Organization Science 12 (2): pp. 198-213.

Burke, R. J. (1995), Benefits of formal training courses within a professional services firm, Journal of Management Development 14 (3): pp. 3-13.

Cangelosi, V. E. and W. R. Dill (1965), Organizational Learning: Observations Toward a Theory, Administrative Science Quarterly 10 (2): pp. 175-203.

Cannon, M. D. and A. C. Edmondson (2005), Failing to Learn and Learning to Fail (Intelligently): How Great Organizations Put Failure to Work to Innovate and Improve, Long Range Planning 38 (3): pp. 299-319.

Carroll, J. S. (1998), Organizational Learning Activities in High-hazard Industries: The Logics Underlying Self-Analysis, Journal of Management Studies 35 (6): pp. 699-717.

Coff, R. W., D. C. Coff and R. Eastvold (2006), The Knowledge-Leveraging Paradox: how to Achieve Scale without Making Knowledge Imitable, Academy of Management Review 31 (2): pp. 452-465.

Cohen, M. D. and P. Bacdayan (1994), Organizational Routines Are Stored As Procedural Memory: Evidence from a Laboratory Study, Organization Science 5 (4): pp. 554-568.

Cohen, W. M. and D. A. Levinthal (1990), Absorptive Capacity: A New Perspective on Learning and Innovation, Administrative Science Quarterly 35 (1, Special Issue: Technology, Organizations, and Innovation): pp. 128-152.

Conger, J. A. and R. N. Kanungo (1988), The Empowerment Process: Integrating Theory and Practice, The Academy of Management Review 13 (3): pp. 471-482.

Cook, S. D. N. and J. S. Brown (1999), Bridging Epistemologies: The Generative Dance between Organizational Knowledge and Organizational Knowing, Organization Science 10 (4): pp. 381-400.

Cook, S. D. N. and D. Yanow (1993), Culture and Organizational Learning, Journal of Management Inquiry 2 (4): pp. 373-390.

Coopey, J. (1995), The Learning Organization, Power, Politics and Ideology, Management Learning 26 (2): pp. 193-213. 
Cyert, R. M. and J. G. March (1963), A Behavioral Theory of the Firm, Prentice-Hall: Englewood Cliffs, NJ.

Chang, L. and B. Birkett (2004), Managing intellectual capital in a professional service firm: exploring the creativity-productivity paradox, Management Accounting Research 15 (1): pp. 7-31.

Cheetham, G. and G. Chivers (2001), How professionals learn in practice: an investigation of informal learning amongst people working in professions, Journal of European Industrial Training 25 (5): pp. 247-292.

Daft, R. L. and K. E. Weick (1984), Toward a Model of Organizations as Interpretation Systems, The Academy of Management Review 9 (2): pp. 284-295.

Davenport, T. H., D. W. De Long and M. C. Beers (1998), Successful Knowledge Management Projects, Sloan Management Review 39 (2): pp. 43-57.

De Geus, A. P. (1988), Planning as Learning, Harvard Business Review 66 (2): pp. 70-74.

Dodgson, M. (1993), Organizational Learning: A Review of Some Literatures, Organization Studies 14 (3): pp. 375-394.

Dreyfus, H. L. (1992), What Computers Still Can't Do: A Critique of Artificial Reason, MIT Press: Cambridge, MA.

Dyck, B., F. A. Starke, G. A. Mischke and M. Mauws (2005), Learning to Build a Car: An Empirical Investigation of Organizational Learning, Journal of Management Studies 42 (2): pp. 387-416.

Easterby-Smith, M. and M. A. Lyles (2003), Introduction: Watersheds of Organizational Learning and Knowledge Management. In M. Easterby-Smith and M. A. Lyles (Eds.), The Blackwell Handbook of Organizational Learning and Knowledge Management: pp. 1-15. Blackwell Publishing: Oxford, UK.

Edmondson, A. (1999), Psychological Safety and Learning Behavior in Work Teams, Administrative Science Quarterly 44 (2): pp. 350-383.

Edmondson, A. C., R. M. Bohmer and G. P. Pisano (2001), Disrupted Routines: Team Learning and New Technology Implementation in Hospitals, Administrative Science Quarterly 46 (4): pp. 685-716.

Edmondson, A. C., A. B. Winslow, R. M. J. Bohmer and G. P. Pisano (2003), Learning How and Learning What: Effects of Tacit and Codified Knowledge on Performance Improvement Following Technology Adoption, Decision Sciences 34 (2): pp. 197-223.

Eisenstein, E. M. and J. W. Hutchinson (2006), Action-Based Learning: Goals and Attention in the Acquisition of Market Knowledge, Journal of Marketing Research (JMR) 43 (2): pp. 244-258.

Empson, L. (2007), Profession, In S. Clegg and J. Bailey (Eds.), International Encyclopedia of Organization Studies, Sage Publications: Oxford.

Epple, D., L. Argote and R. Devadas (1991), Organizational Learning Curves: A Method for Investigating Intra-Plant Transfer of Knowledge Acquired Through Learning by Doing, Organization Science 2 (1): pp. 58-70.

Feldman, D. C. and M. J. Lankau (2005), Executive Coaching: A Review and Agenda for Future Research, Journal of Management 31 (6): pp. 829-848. 
Fiol, C. M. and M. A. Lyles (1985), Organizational Learning, The Academy of Management Review 10 (4): pp. 803-813.

Foster, A. D. and M. R. Rosenzweig (1995), Learning by Doing and Learning from Others: Human Capital and Technical Change in Agriculture, The Journal of Political Economy 103 (6): pp. 1176-1209.

Gallupe, B. (2001), Knowledge management systems: surveying the landscape, International Journal of Management Reviews 3 (1): p. 61.

Gattiker, U. E. (1995), Firm and Taxpayer Returns from Training of Semiskilled Employees, The Academy of Management Journal 38 (4): pp. 1152-1173.

Grossman, S. J., R. E. Kihlstrom and L. J. Mirman (1977), A Bayesian Approach to the Production of Information and Learning by Doing, The Review of Economic Studies 44 (3): pp. 533-547.

Groysberg, B., L. E. Lee and A. Nanda (2008), Can They Take It With Them? The Portability of Star Knowledge Workers' Performance, Management Science 54 (7): pp. 1213-1230.

Gueldenberg, S. and H. Helting (2007), Bridging 'The Great Divide': Nonaka's Synthesis of 'Western' and 'Eastern' Knowledge Concepts Reassessed, Organization 14 (1): pp. 101-122.

Hackman, J. R. and R. Wageman (1995), Total Quality Management: Empirical, Conceptual, and Practical Issues, Administrative Science Quarterly 40 (2): pp. 309-342.

Hansen, M. T., N. Nohria and T. Tierney (1999), What's Your Strategy for Managing Knowledge? Harvard Business Review 77 (2): pp. 106-116.

Hazlett, S. A., R. McAdam and S. A. Gallagher (2005), Theory Building in Knowledge Management, Journal of Management Inquiry 14 (1): pp. 31-42.

Hedberg, B. (1981), How Organizations Learn and Unlearn, In P. C. Nystrom, W. H. Starbuck (Eds.), Handbook of Organizational Design, Vol. 1, Adapting Organizations to Their Environment: 3-27, Oxford University Press: New York, NY.

Herriott, S. R., D. A. Levinthal and J. G. March (1985), Learning from Experience in Organizations, The American Economic Review 75 (2, Papers and Proceedings of the Ninety-Seventh Annual Meeting of the American Economic Association): pp. 298-302.

Hitt, M. A., L. Bierman, K. Shimizu and R. Kochhar (2001), Direct and Moderating Effects of Human Capital on Strategy and Performance in Professional Service Firms: a Resource-Based Perspective, Academy of Management Journal 44 (1): pp. 13-28.

Huber, G. P. (1991), Organizational Learning: The Contributing Processes and the Literatures, Organization Science 2 (1): pp. 88-115.

Hunt, D. M. and C. Michael (1983), Mentorship: A Career Training and Development Tool, The Academy of Management Review 8 (3): pp. 475-485.

Inkpen, A. C. and M. M. Crossan (1995), Believing is Seeing: Joint Ventures and Organization Learning, Journal of Management Studies 32 (5): pp. 595-618.

Jovanovic, B. and Y. Nyarko (1996), Learning by Doing and the Choice of Technology, Econometrica 64 (6): pp. 1299-1310 
Killingsworth, M. R. (1982), "Learning by Doing" and "Investment in Training": A Synthesis of Two "Rival" Models of the Life Cycle, The Review of Economic Studies 49 (2): pp. 263-271.

King, A. W. and A. L. Ranft (2001), Capturing knowledge and knowing through improvisation: what managers can learn from the Thoracic Surgery Board certification process, Journal of Management 27(3): pp. 255-277.

Knoke, D. and A. L. Kalleberg (1994), Job Training in U.S. Organizations, American Sociological Review 59 (4): pp. 537-546.

Kolb, A. Y. and D. A. Kolb (2005), Learning Styles and Learning Spaces: Enhancing Experiential Learning in Higher Education, Academy of Management Learning and Education 4 (2): pp. 193-212.

Lave, J. and E. Wenger (1991), Situated Learning. Legitimate Peripheral Participation, Cambridge University Press: Cambridge, UK; New York, NY

Lee, F., A. C. Edmondson, S. Thomke and M. Worline (2004), The Mixed Effects of Inconsistency on Experimentation in Organizations, Organization Science 15 (3): pp. 310-326.

Lei, D., M. A. Hitt and R. Bettis (1996), Dynamic Core Competences Through Meta-Learning and Strategic Context, Journal of Management 22(4): p. 549.

Levinthal, D. A. and J. G. March (1993), The Myopia of Learning, Strategic Management Journal 14 (Special Issue: Organizations, Decision Making and Strategy): pp. 95-112.

Levitt, B. and J. G. March (1988), Organizational Learning, Annual Review of Sociology 14 (1): pp. 319-338.

Libby, R. and H. T. Tan (1994), Modeling the determinants of audit expertise, Accounting, Organizations and Society 19 (8): pp. 701-716.

Løwendahl, B. R., Ø. Revang and S. M. Fosstenløkken (2001), Knowledge and value creation in professional service firms: A framework for analysis, Human Relations 54 (7): pp. 911-931.

Ma, Z. and K. H. Yu (2010), Research paradigms of contemporary knowledge management studies: 1998-2007, Journal of Knowledge Management 14 (2): pp. 175-189.

Macdonald, S. (1995), Learning to Change: An Information Perspective on Learning in the Organization, Organization Science 6 (5): pp. 557-568.

March, J. G. (1991), Exploration and Exploitation in Organizational Learning, Organization Science 2 (1): pp. 71-87.

March, J. G., L. S. Sproull and M. Tamuz (1991), Learning from Samples of One or Fewer, Organization Science 2 (1): pp. 1-13.

Maritan, C. A. and T. H. Brush (2003), Heterogeneity and Transferring Practices: Implementing Flow Manufacturing in Multiple Plants, Strategic Management Journal 24 (10, Special Issue: Why Is There a Resource-Based View? Toward a Theory of Competitive Heterogeneity): pp. 945-959.

Marshall, N. (2008), Cognitive and Practice-based Theories of Organizational Knowledge and Learning: Incompatible or Complementary?, Management Learning 39 (4): pp. 413-435.

Menger, P. M. (1999). Artistic Labor Markets and Careers. Annual Review of Sociology 25: pp. 541-574. 
Miller, K. D. (2008), Simon and Polanyi on Rationality and Knowledge, Organization Studies 29 (7): pp. 933-955.

Mincer, J. (1962), On-the-Job Training: Costs, Returns, and Some Implications, The Journal of Political Economy 70 (5, Part 2: Investment in Human Beings): pp. 50-79.

Morris, M. W. and P. C. Moore (2000), The Lessons We (Don't) Learn: Counterfactual Thinking and Organizational Accountability after a Close Call, Administrative Science Quarterly 45 (4): pp. 737-765.

Nahapiet, J. and S. Ghoshal (1998), Social Capital, Intellectual Capital, and the Organizational Advantage, The Academy of Management Review 23 (2): pp. 242-266.

Nicolini, D. and M. B. Meznar (1995), The Social Construction of Organizational Learning: Conceptual and Practical Issues in the Field, Human Relations 48 (7): pp. 727-746

Nonaka, I. (1994), A Dynamic Theory of Organizational Knowledge Creation, Organization Science 5 (1): pp. 14-37.

Nonaka, I., G. von Krogh and S. Voelpel (2006), Organizational Knowledge Creation Theory: Evolutionary Paths and Future Advances, Organization Studies 27 (8): pp. 1179-1208.

Pedler, M., T. Boydell and J. Burgoyne (1989), Towards the Learning Company, Management Education and Development 20 (1): pp. 1-8

Penrose, E. T. (1959), The Theory of the Growth of the Firm, Blackwell: Oxford, UK.

Pisano, G. P. (1994), Knowledge, Integration, and the Locus of Learning: An Empirical Analysis of Process Development, Strategic Management Journal 15 (Special Issue: Competitive Organizational Behavior): pp. 85-100.

Pisano, G. P., R. M. J. Bohmer and A. C. Edmondson (2001), Organizational Differences in Rates of Learning: Evidence from the Adoption of Minimally Invasive Cardiac Surgery, Management Science 47 (6): pp. 752-768.

Polanyi, M. (1966), The Tacit Dimension, Doubleday Anchor Books: Garden City, NY.

Polanyi, M. and A. Sen (2009), The Tacit Dimension, University of Chicago Press: Chicago, IL.

Prats, M. J. and R. Agulles (2011), Managing Managers as Professionals: Leadership Development and Talent Transfer in a Global World, In J. Canals (Ed.), The Future of Leadership Development. Corporate Needs and the Role of Business Schools: pp. 266-288. Palgrave Macmillan: Basingstoke, UK.

Raelin, J. A. (1997), A Model of Work-Based Learning, Organization Science 8 (6): pp. 563-578.

Rogers, P. and T. Tierney (2004), Leadership without control, European Business Journal: pp. 78-82.

Salas, E. and J. Cannon-Bowers (2001), The Science of Training: A Decade of Progress, Annual Review of Psychology 52 (1): p. 471.

Sandberg, Jr. and A. H. Pinnington (2009), Professional Competence as Ways of Being: An Existential Ontological Perspective, Journal of Management Studies Early view: pp. 1-33. 
Sapsed, J., J. Bessant, D. Partington, D. Tranfield and M. Young (2002), Teamworking and Knowledge Management: A Review of Converging Themes, International Journal of Management Reviews 4 (1): p. 71.

Senge, P. M. (1990), The fifth discipline: the art and practice of the learning organization, Doubleday/Currency: New York, NY.

Shrivastava, P. (1983), A Typology of Organizational Learning Systems, Journal of Management Studies 20 (1): pp. 7-28.

Simon, H. A. (1991), Bounded Rationality and Organizational Learning, Organization Science 2 (1): pp. 125-134.

Simonin, B. L. (1997), The Importance of Collaborative Know-How: An Empirical Test of the Learning Organization, The Academy of Management Journal 40 (5): pp. 1150-1174.

Sims, R. R. (1983), Kolb's Experiential Learning Theory: A Framework for Assessing Person-Job Interaction, Academy of Management Review 8 (3): pp. 501-508.

Snell, R. and A. M. K. Chak (1998), The Learning Organization: Learning and Empowerment for Whom? Management Learning 29 (3): pp. 337-364.

Snook, S. and R. Khurana (2004), Developing "Leaders of Character": Lessons from West Point, In R. Gandossy and J. Sonnenfeld (Eds.), Leadership and Governance from the Inside Out: pp. 213-233. Wiley: New York.

Soo, C., T. Devinney, D. Midgley and A. Deering (2002), Knowledge Management: Philosophy, Processes, and Pitfalls, California Management Review 44 (4): pp. 129-150.

Spender, J. C. (1996), Making Knowledge the Basis of a Dynamic Theory of the Firm, Strategic Management Journal 17: pp. 45-62.

Spender, J. C. (2008), Organizational Learning and Knowledge Management: Whence and Whither? Management Learning 39 (2): pp. 159-176.

Spender, J. C. and A. G. Scherer (2007), The Philosophical Foundations of Knowledge Management: Editors' Introduction, Organization 14 (1): pp. 5-28.

Stein, E. W. and V. Zwass (1995), Actualizing Organizational Memory with Information Systems, Information Systems Research 6 (2): pp. 85-117.

Stevens, M. J. and M. A. Campion (1994), The Knowledge, Skill, and Ability Requirements for Teamwork: Implications for Human Resource Management, Journal of Management 20 (2): pp. 503-530.

Tan, H. T. and R. Libby (1997), Tacit Managerial versus Technical Knowledge As Determinants of Audit Expertise in the Field, Journal of Accounting Research 35 (1): pp. 97-113.

Teece, D. J. (2003), Expert talent and the design of (professional services) firms, Industrial and Corporate Change 12 (4): pp. 895-916.

Torbert W. R. (1994), Managerial Learning, Organizational Learning, Management Learning 25 (1): pp. 57-70. 
Tsoukas H. (1996), The Firm as a Distributed Knowledge System: A Constructionist Approach, Strategic Management Journal 17: pp. 11-25.

Tucker A. L. and A. C. Edmondson (2003), Why Hospitals Don't Learn from Failures: Organizational and Psychological Dynamics that Inhibit System Change, California Management Review 45 (2): pp. 55-72.

Tucker A. L., A. C. Edmondson and S. Spear (2002), When Problem Solving Prevents Organizational Knowledge. Journal of Organizational Change Management 15 (2): pp. 122-137.

Tucker A. L., I. M. Nembhard and A. C. Edmondson (2007), Implementing New Practices: An Empirical Study of Organizational Learning in Hospital Intensive Care Units, Management Science 53 (6): pp. 894-907.

van der Sluis L., R. Williams and L. Hoeksema (2002), Measuring the quality of managerial learning on the job, International Journal of Human Resource Management 13 (8): pp. 1266-1278.

Weick K. E. and K. H. Roberts (1993), Collective Mind in Organizations: Heedful Interrelating on Flight Decks, Administrative Science Quarterly 38 (3): pp. 357-381.

Wenger E. (1998), Communities of Practice. Learning, Meaning, and Identity, Cambridge University Press: Cambridge, UK; New York, NY.

Wood R. and A. Bandura (1989), Social Cognitive Theory of Organizational Management, The Academy of Management Review 14 (3): pp. 361-384.

Yew E. and H. Schmidt (2009), Evidence for constructive, self-regulatory, and collaborative processes in problem-based learning, Advances in Health Sciences Education 14 (2): pp. 251-273.

Young A. (1993), Invention and Bounded Learning by Doing, The Journal of Political Economy 101 (3): pp. 443-472. 